\title{
A Dynamical Innovation Diffusion Model with Fuzzy Coefficient and Its Application to Local Telephone Diffusion in China
}

\author{
Zhigao Liao, ${ }^{1,2}$ Jiuping $\mathrm{Xu},{ }^{1}$ and Liming $\mathrm{Yao}^{1}$ \\ ${ }^{1}$ Uncertainty Decision-Making Laboratory, Sichuan University, Chengdu 610064, China \\ ${ }^{2}$ Department of Management, Guangxi University of Science and Technology, Liuzhou 545006, China \\ Correspondence should be addressed to Jiuping Xu; xujiuping@scu.edu.cn
}

Received 5 July 2012; Revised 3 December 2012; Accepted 5 December 2012

Academic Editor: Xiang Li

Copyright (c) 2013 Zhigao Liao et al. This is an open access article distributed under the Creative Commons Attribution License, which permits unrestricted use, distribution, and reproduction in any medium, provided the original work is properly cited.

\begin{abstract}
This paper studies the innovation diffusion problem with the affection of urbanization, proposing a dynamical innovation diffusion model with fuzzy coefficient, and uses the shifting rate of people from rural areas stepping into urban areas to show the process of urbanization. The numerical simulation shows the diffusion process for telephones in China with Genetic Algorithms and this model is effective to show the process of innovation diffusion with the condition of urbanization process.
\end{abstract}

\section{Introduction}

Technological innovation promotes the evolution of industries by altering the competitive market structure and value chains of industries [1]. The market success of an innovation is determined not only by technological performance, but also by the interaction of numerous factors. Consequently, it is understandable that many studies choose to investigate the key factors that influence the acceptance or the rejection of an innovation during the process of diffusion. Based on these key factors including price and advertising, researchers have contributed to the development of the diffusion theory by suggesting analytical models for describing and forecasting the diffusion process of an innovation in a social system [216] such researchers include Fourt, Mansfield, and Mahajan. Fourt and Mansfield discussed the diffusion pattern in external influence such as mass advertisement or internal influence such as oral communication separately $[8,12]$. The sales model for forecasting TV made by Bass in 1969 has settled the base for the following research on innovation diffusion with both external factors and internal factors taken into account [3]. However, the potential adopters in these models are static or fixed at the time an innovation is introduced and remains constant over the diffusion process. Obviously, such an assumption is not tenable with regard to either theory or practice.
In response to this shortcoming, Mahajan and Peterson proposed a dynamical diffusion model where the potential is permitted to vary over time [13]. There are many relevant factors affecting the potential, including socioeconomic conditions in the social system, increases or decreases in the population of the social system, government actions, and efforts to influence the diffusion process, such as advertising and pricing. Such a proposition was followed and developed by Lackman, Dodson, and several other researchers [17-24]. Kalish, for example, conjectured that the qualitative structure of an optimal pricing policy will remain the same upon the inclusion of additional marketing variables such as advertising, in the diffusion model. Jain and Rao show that price affects the diffusion rate via the coefficients of external and internal influence [20].

Because different adopters have different attitudes of risk or decisive patterns, there will be great difference in adoption possibility and rate. The consumption habit, the living standard, and the environment around also make a great difference in the adopting rate. For this reason, a diffusion model is presented in a different section in the paper [25]. The author believes that the characteristics of adopters in different patches make differences in the diffusion rate. Furthermore, there will be migration between patches, which would also have an effect on innovation diffusion. With great economic development and urbanization, we 
TABLE 1: The explanation for conversion relation.

Conversion name/way of conversion

(A) External information, oral communication

(B) External information, oral communication

(C) Give up using

(D) Give up using

(E) The members shifting between the colonies

(F) The members shifting between the colonies

(G) The members shifting between the colonies

(H) The members shifting between the colonies

(M) The members shifting between the colonies

(N) The members shifting between the colonies
Explanation for conversion

non-users become users in colony 1

non-users become users in colony 2

Users become Non-users in colony 1

Users become Non-users in colony 2

Users in colony 1 continue using the innovation after shifting into colony 2

Users in colony 2 continue using the innovation after shifting into colony 1

Users in colony 2 give up using the innovation after shifting into colony 1

Users in colony 1 give up using the innovation after shifting into colony 2

Non-users in colony 2 still remain as non-users after shifting into colony 1

Non-users in colony 1 still remain as non-users after shifting into colony 2 should not ignore the potential adopters who have changed their economic conditions or status. They will have great consumption demands for goods which they would not have even considered before. For example, the data of telephone subscribers of China in 2002-2006 has got tremendous growth which cannot be explained by any diffusion model before. Furthermore, the rate of urbanization development is different in different stages. So it is more acceptable if we take the uncertain rate instead of the deterministic rate to simulate the process. We use the rate of people from rural areas stepping into urban to show the process of the urbanization development of this area. Consequently, this paper constructs a fuzzy innovation diffusion model and tries to find the principles of innovation diffusion with the effects of population increasing and urbanization. In this context, model uncertainty is portrayed through the fuzzy transition process from nonuser to the adopter of an innovation because of the uncertain rate of urbanization.

We organize this paper as follows. In Section 2, an innovation diffusion model with the population increasing and the conversion between two different colonies is constructed. In Section 3, a stability analysis is done on the population increasing and the diffusion rate of different groups. An empirical analysis is also done with the data of telephone subscribers of urban and rural areas in China compared with the Bass model in Section 4. Some concluding remarks are finally given in Section 5 .

\section{Modeling}

There is a comparative independence and stability between colony 1 and colony 2. Each of the two colonies has its own main communication styles, broadcasting channels and ways, and consumption habits. However, there also exists migration between them for specific reasons such as improved living standards. The members moving into new community will be accepted into the new consumption system since they are affected by the new environment. In the interior of

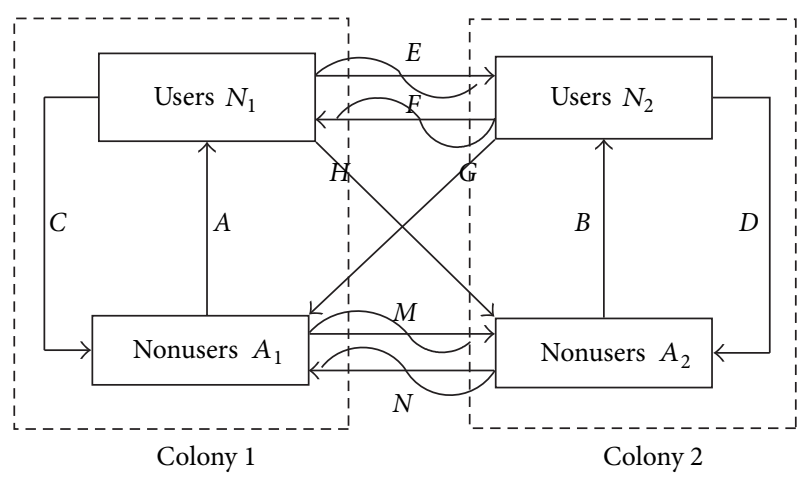

FIGURE 1: Customers flow diagram for innovation between two colonies.

a community, for some related external factors and oral communication, nonusers adopt innovation and serve as users, or users give up the innovation for some reasons after experiencing it.

2.1. Conceptional Model. Based on the foundation above, the concrete convert relations and relations between the inside and outside of the two communities are shown in Figure 1 and Table 1, respectively. The arrowheads denote the flow directions of the members.

\subsection{Mathematical Model}

Hypothesis 1. The members of each colony are divided into users and nonusers. The nonusers include those who adopted the innovation and have given up using it.

Hypothesis 2. The internal increasing rate of the two colonies obeys the logistic distribution functions.

Hypothesis 3. The nonusers of each colony are still nonusers when entering another colony, which can be shown in Figure 1 in the conversion way of $M$ and $N$, and the users of 
each colony can either keep on or give up using the innovation for various reasons when entering another colony.

Hypothesis 4. The number of the members in one colony shifting to another colony is proportional to the number of the total members of the colony, and the coefficient is fuzzy for the uncertainty of urbanization.

Based on the conceptional model, the hypothesis, and the conversion relations above, we build the increase equation for variables $Q_{1}, Q_{2}$, where $Q_{i}(t)$ represents the number of members in colony $i$ in time $t, i=1,2$. According to the empirical statistics, the birthrate and ratio to death are linear functions of the population of the colony. Suppose that $\beta_{i 0}+$ $\left(-d_{i 0} Q_{i}\right)$ is the birthrate of colony $i, \beta_{i 0}$ is the birthrate of colony $i$ without a resource limit, and $-d_{i 0} Q_{i}$ is the birthrate of colony $i$ with a resource limit, where $\beta_{i 0}$ and $d_{i 0}$ are both positive constants. The ratio of death of colony $i$ is $\beta_{i 1}+d_{i 1} Q_{i}>$ 0 , where $\beta_{i 1}$ is the natural death ratio without a resource limit and $d_{i 0} Q_{i}$ is the ratio of death increasing with a resource limit; that is to say, the birthrate will decrease with the increase of population and the death ratio will increase with the increase of population. Thus, the number of members increased in time $t$ in colony 1 is $\left(\beta_{10}-\beta_{11}\right) Q_{1}-\left(d_{10}+d_{11}\right) Q_{1}^{2}$ and $\beta_{10}-\beta_{11}>0$ according to Hypothesis 2 . From Hypothesis 4 and the conversion way of $F$ and $M$, the number of increased members shifting from colony 2 in time $t$ is $\theta_{2} N_{2}+\theta_{2} A_{2}=$ $\theta_{2} Q_{2}$, and the number of members shifting into colony 2 from conversion way of $E$ and $N$ is $\theta_{1} N_{1}+\theta_{1} A_{1}=\theta_{1} Q_{1}$, as seen in Figure 1 . Based on the analysis above, the increase equation of $Q_{1}$ is

$\dot{Q}_{1}=\frac{d Q_{1}}{d t}=\left(\beta_{10}-\beta_{11}\right) Q_{1}-\left(d_{10}+d_{11}\right) Q_{1}^{2}+\theta_{2} Q_{2}-\theta_{1} Q_{1}$.

Similarly, the increase equation of $Q_{2}$ is

$\dot{Q}_{2}=\frac{d Q_{2}}{d t}=\left(\beta_{20}-\beta_{21}\right) Q_{2}-\left(d_{20}+d_{21}\right) Q_{2}^{2}+\theta_{1} Q_{1}-\theta_{2} Q_{2}$.

Consequently the increasing model of colonies' members is governed by

$$
\begin{gathered}
\dot{Q}_{1}=\left(\beta_{10}-\beta_{11}\right) Q_{1}-\left(d_{10}+d_{11}\right) Q_{1}^{2}+\theta_{2} Q_{2}-\theta_{1} Q_{1}, \\
\dot{Q}_{2}=\left(\beta_{20}-\beta_{21}\right) Q_{2}-\left(d_{20}+d_{21}\right) Q_{2}^{2}+\theta_{1} Q_{1}-\theta_{2} Q_{2}, \\
Q_{1}(0)=Q_{10} \geq 0, \quad Q_{2}(0)=Q_{20} \geq 0 .
\end{gathered}
$$

Suppose that $N_{i}(t)$ is the number of users in colony $i$ at time $t$, and $A_{i}(t)$ is the number of nonusers in colony $i$ at time $t$. Now we will build the equation of variable $N_{1}(t)$ in colony 1. From conversion way $A$ in Figure 1, because of the internal oral communication and medium, the number of nonusers who have changed to become users is $a_{1} A_{1}+b_{1} N_{1} A_{1}$, in which $a_{1}$ is the probability for nonusers to become users caused by medium, and $b_{1}$ is the probability for nonusers to become users caused by oral communication between users and nonusers. Owing to natural deaths, the decreasing number of users is $\left(\beta_{11}+d_{11} Q_{1}\right) N_{1}$. From the conversion way $C$ in Figure 1 , there are $e_{1} N_{1}$ users who have to give up using the innovation for some reason, because of movement of population, there are $\theta_{1} N_{1}$ users shifting out of colony 1 and $k_{2} \theta_{2} N_{2}$ users shifting into colony 1 from colony 2 . Here $\theta_{i}$ is the probability for the members of colony $i$ converting into another one and $k_{i}$ is the probability for users to continue using the innovation in colony $i$ after converting into another colony. Based on the analysis above, the increase equation of variable $N_{1}$ is

$$
\begin{aligned}
\dot{N}_{1}=\frac{d N_{1}}{d t}= & a_{1} A_{1}+b_{1} N_{1} A_{1}-\left(\beta_{11}+d_{11} Q_{1}\right) N_{1} \\
& -e_{1} N_{1}-\theta_{1} N_{1}+k_{2} \theta_{2} N_{2} .
\end{aligned}
$$

Similarly, the increase equation of variable $N_{2}$ is

$$
\begin{gathered}
\dot{N}_{2}=\frac{d N_{2}}{d t}=a_{2} A_{2}+b_{2} N_{2} A_{2}-\left(\beta_{21}+d_{21} Q_{2}\right) N_{2} \\
-e_{2} N_{2}-\theta_{2} N_{2}+k_{1} \theta_{1} N_{1} .
\end{gathered}
$$

Consequently, we can say that the dynamical equations of innovation diffusion based on members shifting between colony 1 and colony 2 are governed by

$$
\begin{gathered}
\dot{Q}_{1}=\left(\beta_{10}-\beta_{11}\right) Q_{1}-\left(d_{10}+d_{11}\right) Q_{1}^{2}+\theta_{2} Q_{2}-\theta_{1} Q_{1}, \\
\dot{N}_{1}=a_{1} A_{1}+b_{1} N_{1} A_{1}-\left(\beta_{11}+d_{11} Q_{1}\right) N_{1} \\
-e_{1} N_{1}-\theta_{1} N_{1}+k_{2} \theta_{2} N_{2}, \\
\dot{Q}_{2}=\left(\beta_{20}-\beta_{21}\right) Q_{2}-\left(d_{20}+d_{21}\right) Q_{2}^{2}+\theta_{1} Q_{1}-\theta_{2} Q_{2}, \\
\dot{N}_{2}=a_{2} A_{2}+b_{2} N_{2} A_{2}-\left(\beta_{21}+d_{21} Q_{2}\right) N_{2} \\
-e_{2} N_{2}-\theta_{2} N_{2}+k_{1} \theta_{1} N_{1}, \\
Q_{1}=A_{1}+N_{1}, \\
Q_{2}=A_{2}+N_{2}, \\
Q_{1}(0)=Q_{10} \geq 0, \quad Q_{2}(0)=Q_{20} \geq 0, \\
A_{1}(0)=A_{10} \geq 0, \\
A_{2}(0)=A_{20} \geq 0, \quad N_{1}(0)=N_{10} \geq 0, \\
N_{2}(0)=N_{20} \geq 0 .
\end{gathered}
$$

This model focuses on the analysis of the affection on the customers by the process of urbanization. The urbanization process is expressed by the mutual conversion between various consumer groups. That is to say, with economic development and improved living standards, the low-consumption groups constantly improve their levels of consumption and step into consumer groups of higher levels. From the right expression of the following equation:

$$
\dot{Q}_{1}=\left(\beta_{10}-\beta_{11}\right) Q_{1}-\left(d_{10}+d_{11}\right) Q_{1}^{2}+\theta_{2} Q_{2}-\theta_{1} Q_{1} \text {, }
$$


$\left(\beta_{10}-\beta_{11}\right) Q_{1}-\left(d_{10}+d_{11}\right) Q_{1}^{2}$ is fatally affected by natural population increase, and the policy of family planning, and little affected by economic development, while $\theta_{2} Q_{2}-\theta_{1} Q_{1}$ is mainly affected by economic development. Although certain regularities of economic development can be followed, the effect of this on the customers is uncertain and will vary during the diffusion process of an innovation. However, the models mentioned in the introduction, including system (6), are crisp and obviously cannot meet the actual changes in the law of development. Since these models stressed some main influencing factors, the impact of which on the consumers might be exaggerated, and the combined effects of other factors were ignored, some serious disturbance might occur. Moreover, during the process of diffusion, the impact on the diffusion rate by these factors is of great difference in different stages. For this reason, we try to define $\theta_{i}, i=1,2$ as fuzzy numbers and use fuzzy theory to express the uncertainty of urbanization of China.

\section{The Stability Analysis on the Model}

Since the market is attracted to the variety of innovation users' size and the market potential, we only discuss the variables of members $Q_{1}, Q_{2}$ and the variables of users $N_{1}, N_{2}$. Before discussing the stability of the members increasing model, we will introduce some related concepts and then make the stability analysis on the innovation diffusion.

3.1. Related Concepts. We now recall some definitions needed through the paper.

Let $D^{n}$ denote the set of upper semicontinuous normal fuzzy sets on $R^{n}$ with compact support. That is, if $u \in D^{n}$, then $u: R^{n} \rightarrow[0,1]$ is upper semicontinuous, $\operatorname{supp}(u)=$ $x \in R^{n}: u(x)>0$ is compact, and there exists at least one $\xi \in \operatorname{supp}(u)$ for which $u(\xi)=1$. The $\alpha$-set of $u, 0<\alpha \leq 1$, is

$$
[u]^{\alpha}=\left\{x \in R^{n}: u(x)>\alpha\right\} .
$$

Definition 1. If for $\mu, v \in D^{n}$, there exists $\omega \in D^{n}$ such that $\mu=\nu+\omega$, then we say that the Hukuhara difference of $\mu$ and $v$ exists, call $\omega$ the $H$-difference of $\mu$ and $\nu$, and denote $\mu-\nu=\omega$.

The approach of Hukuhara differentiation suffers a grave disadvantage in so far as the solution has the property that diam $(x(t))$ in nondecreasing in $t$. Consequently, this formulation cannot really reflect any of the reach behaviors of ordinary differential equations such as periodicity, stability, bifurcation, and the like and is ill suited for modeling. However, Hüllermeier suggested a different formulation of the FIVP based on a family of differential inclusions at each $\beta$ level, $0 \leq \beta \leq 1$,

$$
x^{\prime}(t) \in\left[G(t, x(t)]^{\alpha}, \quad x(0) \in\left[x_{0}\right]^{\alpha},\right.
$$

where now $[G(\cdot, \cdot)]^{\alpha}: R \times R^{n} \rightarrow K_{C}^{n}$, the space of nonempty convex compact subsets of $R^{n}$. The idea is that the set of all such solution $\Sigma_{\alpha}\left(X_{0}, t\right)$ would be the $\alpha$ level of a fuzzy set $\Sigma\left(X_{0}, t\right)$ in the sense that all attainable sets $A_{\alpha}\left(X_{0}, t\right)$, $0<t \leq T$, are levels of a fuzzy set $A\left(X_{0}, t\right)$ on $R^{n}$. Considering $\Sigma\left(X_{0}, T\right)$ to be the solution of the fuzzy DE $x^{\prime}=G(t, x), x(0)=X_{0}$, thus captures both uncertainty and the rich properties of differential inclusions in one and the same technique. It has been shown that the solution set and attainability set are fuzzy sets under fairly relaxed conditions on $G[26]$.

Theorem 2 (Staking Theorem [27]). Let $\left\{Y_{\alpha} \subset R^{n} \mid 0 \leq \alpha \leq\right.$ $1\}$ be a family of compact subsets satisfying the following:

(1) $Y_{\alpha} \in F(R)$ for all $0 \leq \alpha \leq 1$;

(2) $Y_{\alpha} \subseteq Y_{\beta}$ for $0 \leq \beta \leq \alpha \leq 1$;

(3) $Y_{\alpha}=\cap_{i=1}^{\infty} Y_{\alpha_{i}}$ for any nondecreasing sequence $\alpha_{i} \rightarrow \alpha$ in $[0,1]$.

Then there is a fuzzy set $u \in D^{n}$ such that $[u]^{\alpha}=Y_{\alpha}$. In particular, if the $Y_{\alpha}$ are also convex, then $u \in \varepsilon^{n}$. Conversely, the level sets $[u]^{\beta}$ of any $u \in D^{n}$ satisfy these conditions, while if $u \in \varepsilon^{n}$, then $[u]^{\alpha}$ are also convex.

Property 1 (Lyapunov Stability, [26]). Let $K \subset R^{n}$ be nonempty and suppose that $G: R^{+} \times K \rightarrow K_{C}^{n}$ be such that initial value problems

$$
x^{\prime} \in G(t, x(t)), \quad t_{0} \leq t<\infty, \quad x\left(t_{0}\right)=x_{0}
$$

have solutions for every $t_{0} \geq 0$ and $x_{0} \in K$. So, the interval of existence of solutions is $J=[0, \infty)$.

A set $M$ is stable for the inclusion (10) if for all $\varepsilon>0$ and $t_{0} \geq 0$, there exists $\delta=\delta\left(\varepsilon, t_{0}\right)>0$ such that $x_{0} \in M+\delta B^{n}$ implies that $x(t) \in M+\varepsilon B^{n}$ on $\left[t_{0}, \infty\right)$ for every solution $x(t)$ of (10). If $A\left(x_{0}, t\right)$ is the attainability set of (10), this may be rephrased as $x_{0} \in M+\delta B^{n}$ implies that $\rho\left(A\left(x_{0}, t\right), M\right) \leq \varepsilon$ on $\left[t_{o}, \infty\right)$. If $\delta=\delta(\varepsilon)$ is independent of $t_{0}$ and depends only on $\varepsilon, M,(10)$ is said to be uniformly stable for the inclusion. If $\rho\left(A\left(x_{0}, t\right), M\right) \leq \varepsilon \rightarrow 0$ as $t \rightarrow \infty$, and $M$ is (uniformly) stable, the set $M$ is said to be (uniformly) asymptotically stable.

Let $H: R \times R^{n} \rightarrow \varepsilon^{n}$, and consider the fuzzy differential equation(FDE):

$$
x^{\prime}=H(t, x), \quad x(0)=X_{0} \in \varepsilon^{n},
$$

interpreted as a family of differential inclusions. Set $[H(t, x)]^{\beta}=F(t, x ; \beta)$ and identify the FDE with the family of differential inclusion:

$$
x_{\beta}^{\prime}(t) \in F\left(t, x_{\beta}(t) ; \beta\right), \quad x_{\beta}(0)=x_{0} \in\left[X_{0}\right]_{\beta}, \quad 0 \leq \beta \leq 1,
$$

where $\Omega$ is an open subset of $R^{n+1}$ containing $\left(0,\left[X_{0}\right]^{0}\right), \beta \epsilon$ $I:=[0,1]$ and $F: \Omega \times I \rightarrow K_{C}^{n}$.

Theorem 3 (see [26]). Let $X_{0} \in \varepsilon^{n}$, and let $\Omega$ be an open set in $R \times R^{n}$ containing $\{0\} \times \operatorname{supp}\left(X_{0}\right)$. Suppose that $H: \Omega \rightarrow \varepsilon^{n}$ is upper semicontinuous and write $F(t, x ; \beta)=[H(t, x)]^{\beta} \in K_{C}^{n}$ for all $(t, x, \beta) \in R^{n+1} \times[0,1]$. Let the boundedness assumption 
with constants $b, M, T$ hold for all $x_{0} \in \operatorname{supp}\left(X_{0}\right)$ and the inclusion:

$$
x^{\prime}(t) \in F(t, x ; 0), \quad x(0) \in \operatorname{supp}\left(X_{0}\right) .
$$

Then the attainable sets $A_{\beta}\left(X_{\beta}, T\right), \beta \in[0,1]$ of the family of inclusions

$$
x_{\beta}^{\prime}(t) \in F\left(t, x_{\beta} ; \beta\right) ; \quad x_{\beta}(0) \in X_{\beta}:=\left[X_{0}\right]^{\beta}, \quad \beta \in[0,1]
$$

are the level sets of a fuzzy set $A\left(X_{0}, T\right) \subset D^{n}$. The solution sets $\Sigma_{\beta}\left(X_{\beta}, T\right)$ of (14) are the level sets of a fuzzy set $\Sigma\left(X_{0}, T\right)$ defined on $Z_{T}\left(R^{n}\right)$, where $Z_{T}\left(R^{n}\right)=\left\{x(\cdot) \in C\left([0, T] ; R^{n}\right)\right.$ : $\left.\left.x^{\prime}(\cdot) \in L^{\infty}([0, T]) ; R^{n}\right)\right\}$.

Property 2 (Lyapunov Stability of a Family of Differential Inclusion, [26]). If $U \in D^{n}$ is a fuzzy set and $\mathbf{U}, \mathbf{W} \subset D^{n}$ are closed subsets of $D^{n}$, define the distance from $\mathbf{W}$ and Hausdorff separation, respectively, by

$$
\begin{gathered}
\rho_{*}(U, \mathbf{W})=\inf _{W \in \mathbf{W}} d_{\infty}(U, W), \\
\rho_{D}(\mathbf{U}, \mathbf{W})=\sup _{U \in \mathbf{U}} \rho_{*}(U, \mathbf{W}) .
\end{gathered}
$$

The significance of these definitions is that the metric space $\left(D^{n}, d_{\infty}\right)$ of fuzzy sets, $\rho_{*}(U, \mathbf{W})$, is the distance of $U \in D^{n}$ from $\mathbf{W} \subset D^{n}$ and is the analogue of $\rho(x, A)$ in $R^{n}$. Correspondingly, $\rho_{D}(\mathbf{U}, \mathbf{W})$ is the Hausdorff separation between $\mathbf{U}, \mathbf{W} \subset D^{n}$ with respect to the metric $d_{\infty}$ and is the analogue of the Hausdorff separation $\rho(A, B)$ in $K^{n}$.

Let 0 be the fuzzy singleton $\chi_{\{0\}} \in D^{n}$, write $\|U\|=$ $d_{\infty}(U, 0)$, and denote the open unit ball in $D^{n}$ by $B^{n}=\{U \in$ $\left.D^{n}:\|U\|<1\right\}$.

A set $\mathbf{U} \subset D^{n}$ is stable for the FDE (12) if for all $\varepsilon>0$ and $t_{0} \geq 0$ there exists $\delta=\delta\left(\varepsilon, t_{0}\right)$ such that $X_{0} \in \mathbf{U}+\delta B^{n}$ implies that $A\left(X_{0}, t\right) \in \mathbf{U}+\varepsilon B^{n}$ on $\left[t_{0}, \infty\right)$, where $A\left(X_{0}, t\right)$ is the fuzzy attainability set defined by the family (12); that is, $\rho_{*}\left(X_{0}, \mathbf{U}\right)<\delta$ implies that $\rho_{D}\left(A\left(X_{0}, t\right), \mathbf{U}\right) \leq \varepsilon$ on $\left[t_{0}, \infty\right)$. If $\delta=\delta(\varepsilon)$ is independent of $t_{0}$ and depends only on $\varepsilon$, $\mathbf{U}$ for the FDE (12) is said to be uniformly stable. If $\rho_{D}\left(A\left(X_{0}, t\right), \mathbf{U}\right) \rightarrow$ 0 as $t \rightarrow \infty$ and $\mathbf{U}$ is (uniformly) stable, the set $\mathbf{U}$ is said to be (uniformly) asymptotically stable. Most frequently, $\mathbf{U}$ will consist of a single fuzzy set $U \in D^{n}$.

Theorem 4. Let $E$ be an open subset of $D^{n}$ containing the origin, let $F \in C^{1}(E)$, and let $\phi_{t}$ be the flow of the nonlinear system (12). Suppose that $F(0)=0$ and that $D F(0)$ has $k$ eigenvalues with negative real part and $n-k$ eigenvalues with positive real part. Then there exists a $k$-dimensional differentiable manifold $S$ tangent to the stable subspace $E^{S}$ of the linear differential inclusions:

$$
x_{\beta}^{\prime}(t) \in D F(0) x_{\beta}(t), \quad x_{\beta}(0)=x_{0} \in\left[X_{0}\right]_{\beta}, \quad 0 \leq \beta \leq 1
$$

at 0 such that for all $t \geq 0, \phi_{t}(S) \subset S$ and for all $\left[X_{0}\right]_{\beta} \in S$,

$$
\lim _{t \rightarrow \infty} \phi_{t}\left(x_{0}, \beta\right)=0 \text {, }
$$

and there exists an $n-k$-dimensional differentiable manifold $U$ tangent to the unstable subspace $E^{U}$ of (16) at 0 such that for all $t \leq 0, \phi_{t}(U) \subset U$ and for all $x_{0} \in U$,

$$
\lim _{t \rightarrow-\infty} \phi_{t}\left(x_{0}, \beta\right)=0 .
$$

Proof. If $F \in C^{1}(E)$ and $F(0)=0$, system (12) can be written as

$$
\begin{gathered}
x_{\beta}^{\prime}(t) \in A_{\beta} x+f\left(t, x_{\beta}(t) ; \beta\right), \\
x_{\beta}(0)=x_{0} \in\left[X_{0}\right]_{\beta}, \quad 0 \leq \beta \leq 1,
\end{gathered}
$$

where $A_{\beta}=D F(0), f(x)=F(x)-A_{\beta} x, f \in C^{1}(E), f(0)=0$, and $D f(0)=0$. This in turn implies that for all $\varepsilon>0$, there is a $\delta>0$ such that $|x| \leq \delta$ and $|y| \leq \delta$ imply that

$$
|f(x)-f(y)| \leq \varepsilon|x-y| .
$$

Furthermore, for all matrix $A_{0} \in A_{\beta}$ there is an $n \times n$ invertible matrix $C_{0}$ such that

$$
B_{0}=C_{0}^{-1} A_{0} C_{0}=\left[\begin{array}{cc}
P_{0} & 0 \\
0 & Q_{0}
\end{array}\right]
$$

in which the eigenvalues of $k \times k$ matrix $P_{0}$ have negative real part and the eigenvalues of the $(n-k) \times(n-k)$ matrix $Q_{0}$ have positive real part. We can choose $\alpha>0$ sufficiently small that for $j=1, \ldots, k$,

$$
\operatorname{Re}\left(\lambda_{j}\right)<-\alpha<0 .
$$

Letting $y=C^{-1} x, C=\left\{C_{0} \mid B_{0}=C_{0}^{-1} A_{0} C_{0}, A_{0} \in A_{\beta}\right\}$ the system (19) then has the form

$$
\dot{y}_{\beta} \in B_{\beta} y_{\beta}+G\left(y_{\beta}\right),
$$

where $B_{\beta}=\left\{B_{0}=C_{0}^{-1} A_{0} C_{0} \mid A_{0} \in A_{\beta}\right\}, G\left(y_{\beta}\right)=C^{-1} f$ $\left(C y_{\beta}\right) \in C^{1}(\breve{E})$, where $\breve{E}=C^{-1}(E)$ and $G$ satisfies the Lipschitz-type condition (20) above.

Consider the system (23). Let

$$
U_{\beta}(t)=\left[\begin{array}{cc}
e^{P_{\beta} t} & 0 \\
0 & 0
\end{array}\right], \quad V_{\beta}(t)=\left[\begin{array}{cc}
0 & 0 \\
0 & e^{Q_{\beta} t}
\end{array}\right],
$$

where $P_{\beta}=\left\{P_{0} \mid B_{0}=C_{0}^{-1} A_{0} C_{0}, A_{0} \in A_{\beta}\right\}, Q_{\beta}=\left\{Q_{0} \mid\right.$ $\left.B_{0}=C_{0}^{-1} A_{0} C_{0}, A_{0} \in A_{\beta}\right\}$. Then, for $\forall U_{0} \in U_{\beta}$ and $\forall V_{0} \in V_{\beta}$, $\dot{U}_{0} \in B_{\beta} U_{\beta}, \dot{V}_{0} \in B_{\beta} V_{\beta}$, and

$$
e^{B_{\beta} t}=U_{\beta}(t)+V_{\beta}(t) .
$$

It is not difficult to see that with $\alpha>0$ chosen in (22), we can choose $K>0$ sufficiently large and $\sigma>0$ sufficiently small that

$$
\begin{gathered}
\max _{0 \leqslant \beta \leqslant 1}\left\|U_{\beta}(t)\right\| \leq K e^{-(\alpha+\sigma) t} \quad t \geq 0, \\
\max _{0 \leqslant \beta \leqslant 1}\left\|V_{\beta}(t)\right\| \leq K e^{\sigma t} \quad t \leq 0,
\end{gathered}
$$


Next consider the integral equation:

$$
\begin{aligned}
u(t, a, \beta)= & U_{\beta}(t) a+\int_{0}^{t} U_{\beta}(t-s) G(u(t, a, \beta)) \mathrm{d} s \\
& -\int_{t}^{\infty} V_{\beta}(t-s) G(u(t, a, \beta)) \mathrm{d} s .
\end{aligned}
$$

If $u(t, a, \beta)$ is a continuous solution of this integral equation, then it is a solution of the differential inclusion (23). We now solve this integral equation by the method of successive approximations. Let

$$
\begin{gathered}
u^{(0)}(t, a, \beta)=0 \\
u^{(j+1)}(t, a, \beta)=U_{\beta}(t) a+\int_{0}^{t} U_{\beta}(t-s) G^{(j)}(u(s, a, \beta)) \mathrm{d} s \\
-\int_{t}^{\infty} V_{\beta}(t-s) G^{(j)}(u(s, a, \beta)) \mathrm{d} s .
\end{gathered}
$$

Assume that the induction hypothesis

$$
\left|u^{(j)}(t, a, \beta)-u^{(j-1)}(t, a, \beta)\right| \leq \frac{K|a| e^{-\alpha t}}{2^{j-1}}
$$

holds for $j=1,2, \ldots, m$ and $t \geq 0$. It clearly holds for $j=1$, provided $t \geq 0$. Then using the Lipschitz-type condition (20) satisfied by the function $G$ and the above estimates on $\left\|U_{\beta}(t)\right\|$ and $\left\|V_{\beta}(t)\right\|$, it follows from the induction hypothesis that for $t \geq 0,0 \leqslant \beta \leqslant 1$,

$$
\begin{aligned}
\left|u^{(m+1)}(t, a, \beta)-u^{(m)(t, a, \beta)}\right| & \\
\leq & \int_{0}^{t}\left\|U_{\beta}(t-s)\right\| \varepsilon\left|u^{(m)}(t, a, \beta)-u^{(m-1)}(t, a, \beta)\right| \mathrm{d} s \\
& +\int_{t}^{\infty}\left\|V_{\beta}(t-s)\right\| \varepsilon\left|u^{(m)}(t, a, \beta)-u^{(m-1)}(t, a, \beta)\right| \mathrm{d} s \\
\leq & \varepsilon \int_{0}^{t} K e^{-(a+\sigma)(t-s)} \frac{K|a| e^{-\alpha s}}{2^{m-1}} \mathrm{~d} s \\
& +\varepsilon \int_{t}^{\infty} K e^{\sigma(t-s)} \frac{K|a| e^{-\alpha s}}{2^{m-1}} \mathrm{~d} s \\
\leq & \frac{\varepsilon K^{2}|a| e^{-\alpha t}}{\sigma 2^{m-1}}+\frac{\varepsilon K^{2}|a| e^{-\alpha t}}{\sigma 2^{m-1}} \\
< & \left(\frac{1}{4}+\frac{1}{4}\right) \frac{K|a| e^{-\alpha t}}{2^{m-1}}=\frac{K|a| e^{-\alpha t}}{2^{m}}
\end{aligned}
$$

provided $\varepsilon K / \sigma<1 / 4$, that is, provided we choose $\varepsilon<\sigma / 4 K$. In order that the condition (20) for the function $G$, it suffices to choose $K|a|<\sigma / 2$; that is, we choose $|a|<\sigma / 2 K$. It then follows by induction that (30) holds for all $j=1,2,3, \ldots$ and $t \geq 0$. Thus, for $n>m>N$ and $t \geq 0$,

$$
\begin{aligned}
& \left|u^{(n)}(t, a, \beta)-u^{(m)}(t, a, \beta)\right| \\
& \quad \leq \sum_{j=N}^{\infty}\left|u^{(j+1)}(t, a, \beta)-u^{(j)}(t, a, \beta)\right| \\
& \quad \leq K|a| \sum_{j=N}^{\infty} \frac{1}{2^{j}}=\frac{K|a|}{2^{N-1}} .
\end{aligned}
$$

This last quantity approaches zero as $N \rightarrow \infty$ and therefore $\left\{u^{(j)}(t, a, \beta)\right\}$ is a Cauchy sequence of continuous functions. Then we have

$$
\lim _{j \rightarrow \infty} u^{(j)}(t, a, \beta)=u(t, a, \beta)
$$

uniformly for all $t \geq 0$ and $|a|<\delta / 2 K$. Taking the limit of both sides of (29), it follows from the uniform convergence that the continuous function $u(t, a, \beta)$ satisfies the integral equation (27) and hence the differential equation (23). It follows by induction and the fact that $G \in C^{1}(\breve{E})$ that $u^{(j)}(t, a, \beta)$ is a differentiable function of $a$ for $t \geq 0$ and $|a|<\delta / 2 K$. Thus, it follows from the uniform convergence that $u(t, a, \beta)$ is a differentiable function of $a$ for $t \geq 0$ and $|a|<\delta / 2 K$. The estimate implies that

$$
|u(t, a, \beta)| \leq 2 K|a| e^{-a t}
$$

for $t \leq 0$ and $|a|<\delta / 2 K$.

It is clear from the integral equation (27) that the last $n-k$ components of vector $a$ do not enter computation and hence they may be taken as 0 . Thus, the components $u_{j}(t, a, \beta)$ of the solution $u(t, a, \beta)$ satisfy the initial conditions:

$$
\begin{gathered}
u_{j}(0, a, \beta)=a_{j} \quad j=1, \ldots, k, \\
u_{j}(0, a, \beta)=-\int_{0}^{\infty} V_{\beta}(-s) G\left(u\left(s, a_{1}, \ldots, a_{k}, 0, \beta\right)\right) \mathrm{d} s \\
j=k+1, \ldots, n,
\end{gathered}
$$

for $j=k+1, \ldots, n$. We define the functions

$$
\psi_{j}\left(a_{1}, \ldots, a_{k}\right)=u_{j}\left(0, a_{1}, \ldots, a_{k}, 0, \ldots, 0, \beta\right) .
$$
satisfy

Then the initial values $y_{j}=u_{j}\left(0, a_{1}, \ldots, a_{k}, 0, \ldots, 0, \beta\right)$

$$
y_{j}=\psi_{j}\left(y_{1}, \ldots, y_{k}\right) \quad j=k+1, \ldots, n .
$$

according to the definition (36). These equations then define a differentiable manifold $\breve{S}$ for $\sqrt{y_{1}^{2}+\cdots+y_{k}^{2}}<\delta / 2 K$. Furthermore, if $y(t)$ is a solution of the differential inclusion (23) with $y(0) \in \breve{S}$, that is, with $y(0)=u(0, a, \beta)$, then

$$
y(t)=u(t, a, \beta) .
$$


It follows that if $y(t)$ is a solution of (23) with $y(0) \in \breve{S}$, then $y(t) \in \breve{S}$ for all $t \geq 0$ and it follows from the estimate (34) that $y(t) \rightarrow 0$ as $t \rightarrow 0$. It can also be shown that if $y(t)$ is a solution of (23) with $y(0)$ not $\in \breve{S}$, then $y(t) \nrightarrow 0$ as $t \rightarrow \infty$. From definition (36) we have

$$
\frac{\partial \psi_{j}}{\partial y_{i}}(0)=0
$$

for $i=1, \ldots, k$ and $j=k+1, \ldots, n$; that is, the differentiable manifold $\breve{S}$ is tangent to the stable subspace $E^{S}=\left\{y_{1}=\cdots=\right.$ $\left.y_{k}=0\right\}$ of the linear system $\dot{y}_{\beta} \in B_{\beta} y_{\beta}$ at 0 .

The existence of the unstable manifold $\breve{U}$ of (23) is established in exactly the same way by considering the system (23) with $t \rightarrow-t$; that is,

$$
\dot{y}_{\beta} \in-B_{\beta} y_{\beta}-G\left(y_{\beta}\right) .
$$

The stable manifold for this system will then be the unstable manifold $\breve{U}$ for (23). Note that it is also necessary to replace the vector $y$ by the vector $\left(y_{k+1}, \ldots, y_{n}, y_{1}, \ldots, y_{k}\right)$ in order to determine the $n-k$-dimensional manifold $\breve{U}$ by the above process. This completes the proof.

If the original point is replaced with the equilibrium point $x$, fussify it and the $\beta$ level set of $x$ is called equilibrium core, denoted by $x_{\beta}$. Now we prove that $\forall x^{*} \in x_{\beta}$ such as Theorem 4; that is, $F\left(x^{*}\right)=0$ and $D F\left(x^{*}\right)$ has $k$ eigenvalues with negative real part and $n-k$ eigenvalues with positive real part, then there exists a $k$-dimensional differentiable manifold $S$ tangent to the stable subspace $E^{S}$ of the linear differential inclusions (16) at $x^{*}$ such that for all $t \geq 0$, $\phi_{t}(S) \subset S$ and for all $\left[x_{0}\right]_{\beta} \in S$,

$$
\lim _{t \rightarrow \infty} \phi_{t}\left(x_{0}, \beta\right)=x^{*},
$$

then the equilibrium core $x_{\beta}$ is stable, and there exists an $n-$ $k$-dimensional differentiable manifold $U$ tangent to unstable subspace $E^{U}$ of (16) at $x^{*}$ such that for all $t \leq 0, \phi_{t}(U) \subset U$ and for all $x_{0} \in U$,

$$
\lim _{t \rightarrow-\infty} \phi_{t}\left(x_{0}, \beta\right)=x^{*},
$$

then the equilibrium core $x_{\beta}$ is stable.

For all $x^{*} \in x_{\beta}$ corresponding to $E^{S}$,

$$
\lim _{t \rightarrow \infty} \phi_{t}\left(x_{0}, \beta\right)=x^{*} .
$$

That is, $\exists t_{0}$, if $t>t_{0}$,

$$
\begin{gathered}
\rho_{*}\left(x^{*}, \phi_{t}\left(x_{0}, \beta\right)\right)<\varepsilon, \\
\rho_{D}\left(x_{\beta}, \phi_{t}\left(x_{0}, \beta\right)\right) \leqslant \rho_{*}\left(x^{*}, \phi_{t}\left(x_{0}, \beta\right)\right)<\varepsilon .
\end{gathered}
$$

According to Property 2 , set $x_{\beta}$ to be stable. Similarly, the equilibrium core $x_{\beta}$ corresponding to $E^{U}$ is unstable and can be proved in the same way.

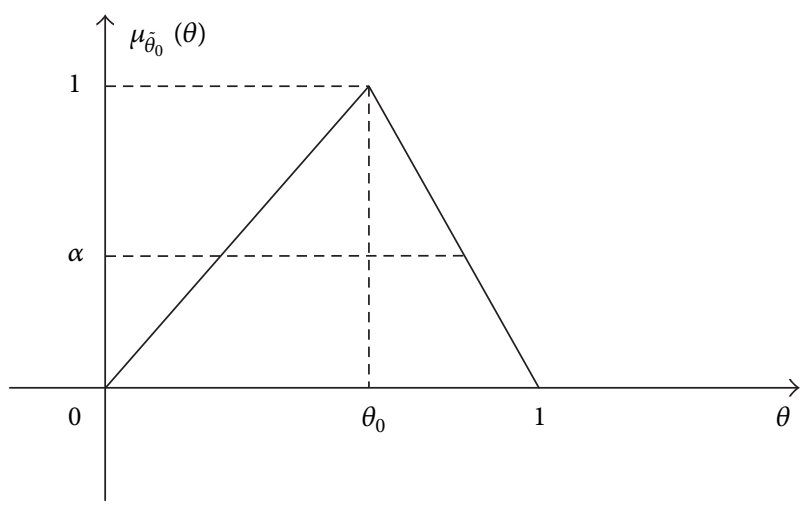

FIgURE 2: The definition of triangular fuzzy number.

3.2. Stability Analysis on Colonies' Members. Here we will discuss the stability of the colonies' members based on the the following different cases: (a) there is no shifting between members of different colonies; (b) one colony's members shift into another while another's members do not; (c) the two colonies' members are shifting into another, respectively.

In this section, we define $\theta$ as triangular fuzzy numbers, just as Figure 2. From Figure $2, \theta_{\alpha} \in\left[\alpha \theta_{0}, 1-\left(\left(1-\theta_{0}\right) / \theta_{0}\right) \alpha\right]$. And $\theta_{i}, i=1,2$ in system (6) follow this definition.

Theorem 5. Suppose that $\left[\theta_{1}\right]_{\alpha}=\left[\theta_{2}\right]_{\alpha}=0$, system (3) has one and only one positive equilibrium core, which is stable in $R_{+}^{2}$.

Proof. If $\left[\theta_{1}\right]_{\alpha}=\left[\theta_{2}\right]_{\alpha}=0$, system (3) has four equilibrium cores $(0,0),\left(M_{10}, 0\right),\left(0, M_{20}\right),\left(M_{10}, M_{20}\right)$, where $M_{10}=$ $\left(\beta_{10}-\beta_{11}\right) /\left(d_{10}+d_{11}\right), M_{20}=\left(\beta_{20}-\beta_{21}\right) /\left(d_{20}+d_{21}\right)$. It is easy to achieve that the equilibrium cores $(0,0),\left(M_{10}, 0\right),\left(0, M_{20}\right)$ are unstable and equilibrium core $\left(M_{10}, M_{20}\right)$ is stable. So $\left(M_{10}, M_{20}\right)$ is stable in $R_{+}^{2}$. This completes the proof.

This indicates that if there is no shifting between the two colonies, the members of the two colonies will trend their maximum eventually and maintain stability.

Theorem 6. Supposing $\left[\theta_{1}\right]_{\alpha}=0,\left[\theta_{2}\right]_{\alpha}>0$, if $\beta_{20}-\beta_{21}-$ $\left[\theta_{2}\right]_{\alpha}>0$, system (3) has one and only one positive equilibrium core, which is stable in $R_{+}^{2}$.

Proof. If $\left[\theta_{1}\right]_{\alpha}=0,\left[\theta_{2}\right]_{\alpha}>0$, system (3) is reduced to

$$
\left(\begin{array}{c}
\dot{Q}_{1 \alpha} \\
\dot{Q}_{2 \alpha}
\end{array}\right) \in\left(\begin{array}{l}
\left(\beta_{10}-\beta_{11}\right) Q_{1 \alpha}-\left(d_{10}+d_{11}\right) Q_{1 \alpha}^{2}+\left[\theta_{2}\right]_{\alpha} Q_{2 \alpha} \\
\left(\beta_{20}-\beta_{21}\right) Q_{2 \alpha}-\left(d_{20}+d_{21}\right) Q_{2 \alpha}^{2}-\left[\theta_{2}\right]_{\alpha} Q_{2 \alpha}
\end{array}\right) .
$$

Obviously, when $\beta_{20}-\beta_{21}-\left[\theta_{2}\right]_{\alpha}>0, M_{20}=\left(\beta_{20}-\beta_{21}-\right.$ $\left.\left[\theta_{2}\right]_{\alpha}\right) /\left(d_{20}+d_{21}\right)$ is stable for the second equation of system (45). Suppose that $M_{10}$ is a positive solution of the following equation:

$$
\left(\beta_{10}-\beta_{11}\right) Q_{1}-\left(d_{10}+d_{11}\right) Q_{1}^{2}+\left[\theta_{2}\right]_{\alpha} Q_{20}=0
$$

then

$$
M_{10}=\frac{\beta_{10}-\beta_{11}+\sqrt{\left(\beta_{10}-\beta_{11}\right)^{2}+4\left(d_{10}+d_{11}\right)\left[\theta_{2}\right]_{\alpha} M_{20}}}{2\left(d_{10}+d_{11}\right)}
$$


and system (45) has unique positive equilibrium core $\left(M_{10}, M_{20}\right)$.

Assuming $Q_{10}=Q_{1}-M_{10}, Q_{20}=Q_{2}-M_{20}$, and $\beta_{i}=$ $\beta_{i 0}-\beta_{i 1}, d_{i}=d_{i 0}+d_{i 1}$, system (45) can be written as

$$
\begin{aligned}
& \left(\begin{array}{c}
\dot{Q}_{10 \alpha} \\
\dot{Q}_{20 \alpha}
\end{array}\right) \\
& \in\left(\begin{array}{l}
\beta_{1}\left(Q_{10 \alpha}+M_{10}\right)-d_{1}\left(Q_{10 \alpha}+M_{10}\right)^{2}+\left[\theta_{2}\right]_{\alpha}\left(Q_{20 \alpha}+M_{20}\right) \\
\beta_{2}\left(Q_{20 \alpha}+M_{20}\right)-d_{2}\left(Q_{20 \alpha}+M_{20}\right)^{2}-\left[\theta_{2}\right]_{\alpha}\left(Q_{20 \alpha}+M_{20}\right)
\end{array}\right)
\end{aligned}
$$

then the coefficient matrix of the linear system of system (48) is

$$
\begin{aligned}
& {\left[\begin{array}{cc}
\beta_{1}-2 d_{1} M_{10} & {\left[\theta_{2}\right]_{\alpha}} \\
0 & \beta_{2}-2 d_{2} M_{20}-\left[\theta_{2}\right]_{\alpha}
\end{array}\right]} \\
& =\left[\begin{array}{cc}
-\sqrt{\beta_{1}^{2}+4 d_{1}\left[\theta_{2}\right]_{\alpha} M_{20}} & {\left[\theta_{2}\right]_{\alpha}} \\
0 & -\sqrt{\beta_{2}^{2}+4 d_{2}\left[\theta_{2}\right]_{\alpha} M_{20}}
\end{array}\right] .
\end{aligned}
$$

The feature values of it are both less than 0 , so the equilibrium core is stable.

Consequently, if $\beta_{20}-\beta_{21}-\left[\theta_{2}\right]_{\alpha}>0$, the equilibrium core $\left(M_{10}, M_{20}\right)$ is stable in $R_{+}^{2}$. This completes the proof.

This indicates that if there is only one colony's member shifting into another while the other's members are not shifting, the members of the two colonies will trend their maximum eventually and maintain stability if satisfying some certain conditions.

Theorem 7. Supposing $\left[\theta_{1}\right]_{\alpha}>0,\left[\theta_{2}\right]_{\alpha}>0$, system (3) has one and only one positive equilibrium core, which is stable in $R_{+}^{2}$.

Proof. If $\left[\theta_{1}\right]_{\alpha}>0,\left[\theta_{2}\right]_{\alpha}>0$, we will show that system (3) has a unique positive equilibrium core. By setting the right-hand side of (3) to 0 , we obtain

$$
\begin{gathered}
f_{1}=Q_{2}=\frac{\left(-\beta_{1}+\left[\theta_{1}\right]_{\alpha}\right) Q_{1}+d_{1} Q_{1}^{2}}{\left[\theta_{2}\right]_{\alpha}}, \\
f_{2}=Q_{1}=\frac{\left(-\beta_{2}+\theta_{2}\right) Q_{2}+d_{2} Q_{2}^{2}}{\left[\theta_{1}\right]_{\alpha}}, \\
\frac{d f_{1}\left(Q_{1}\right)}{d Q_{1}}=\frac{\left(-\beta_{1}+\left[\theta_{1}\right]_{\alpha}\right)+2 d_{1} Q_{1}}{\left[\theta_{2}\right]_{\alpha}}, \\
\frac{d f_{2}\left(Q_{2}\right)}{d Q_{2}}=\frac{\left(-\beta_{2}+\left[\theta_{2}\right]_{\alpha}\right)+2 d_{2} Q_{2}}{\left[\theta_{1}\right]_{\alpha}}, \\
\frac{d f_{1}^{2}\left(Q_{1}\right)}{d Q_{1}^{2}}=\frac{2 d_{1}}{\left[\theta_{2}\right]_{\alpha}}, \quad \frac{d f_{2}^{2}\left(Q_{1}\right)}{d Q_{2}^{2}}=\frac{2 d_{2}}{\left[\theta_{1}\right]_{\alpha}} .
\end{gathered}
$$

By the equation $\left(-\beta_{2}+\left[\theta_{2}\right]_{\alpha}\right) Q_{2}+d_{2} Q_{2}^{2}-Q_{1}\left[\theta_{1}\right]_{\alpha}=0$, we have

$$
\begin{aligned}
h\left(Q_{1}\right) & =Q_{2} \\
& =\frac{\left[\left(\beta_{2}-\left[\theta_{2}\right]_{\alpha}\right)+\sqrt{\left(\beta_{2}-\left[\theta_{2}\right]_{\alpha}\right)^{2}+4 d_{2} Q_{1}\left[\theta_{1}\right]_{\alpha}}\right]}{2 d_{2}} .
\end{aligned}
$$

It is easy to see that $h\left(Q_{1}\right)>0, d h\left(Q_{1}\right) / d Q_{1}>0$, $d h^{2}\left(Q_{1}\right) / d Q_{1}^{2}>0$; therefore, $h\left(Q_{1}\right)$ is convex. Notice that $f_{1}(0)=0, h(0)=0, \lim _{\mathrm{Q}_{1} \rightarrow+\infty}\left[f_{1}\left(Q_{1}\right)-h\left(Q_{1}\right)\right]=+\infty$ and that $f_{1}$ is concave. The parabolic curves have one and only one positive equilibrium core $M\left(M_{10}, M_{20}\right)$. Now we will prove that the equilibrium core is stable. Supposing $Q_{10}=Q_{1}-M_{10}$, $Q_{20}=Q_{2}-M_{20}$, and $\beta_{i}=\beta_{i 0}-\beta_{i 1}-\theta_{i}, d_{i}=d_{i 0}+d_{i 1}$, system

(3) can be written as

$$
\begin{aligned}
& \left(\begin{array}{c}
\dot{Q}_{10 \alpha} \\
\dot{Q}_{20 \alpha}
\end{array}\right) \\
& \epsilon\left(\begin{array}{l}
\beta_{1}\left(Q_{10 \alpha}+M_{10}\right)-d_{1}\left(Q_{10 \alpha}+M_{10}\right)^{2}+\left[\theta_{2}\right]_{\alpha}\left(Q_{20 \alpha}+M_{20}\right) \\
\beta_{2}\left(Q_{20 \alpha}+M_{20}\right)-d_{2}\left(Q_{20 \alpha}+M_{20}\right)^{2}+\left[\theta_{1}\right]_{\alpha}\left(Q_{10 \alpha}+M_{10}\right)
\end{array}\right) .
\end{aligned}
$$
(52) is

Then the coefficient matrix of the linear system of system

$$
\left[\begin{array}{cc}
\beta_{1}-2 d_{1} M_{10} & {\left[\theta_{2}\right]_{\alpha}} \\
{\left[\theta_{1}\right]_{\alpha}} & \beta_{2}-2 d_{2} M_{20}
\end{array}\right] .
$$

Now let us check $\operatorname{Tr} A=\beta_{1}-2 d_{1} M_{10}+\beta_{2}-2 d_{2} M_{20}<0$, $\operatorname{det} A=\left(\beta_{1}-2 d_{1} M_{10}\right)\left(\beta_{2}-2 d_{2} M_{20}\right)-\left[\theta_{1}\right]_{\alpha}\left[\theta_{2}\right]_{\alpha}>0$ and $(\operatorname{Tr} A)^{2}-t \operatorname{det} A>0$,

$$
\begin{aligned}
& M_{10} M_{20} \times \operatorname{Tr} A \\
& \quad=\left(\beta_{1}-2 d_{1} M_{10}+\beta_{2}-2 d_{2} M_{20}\right) M_{10} M_{20} \\
& \quad=M_{20}\left(\beta_{1} M-2 d_{1} M_{10}^{2}\right)+\left(\beta_{2} M_{20}-2 d_{2} M_{20}^{2}\right) M_{20}
\end{aligned}
$$

and since $M\left(M_{10}, M_{20}\right)$ is the equilibrium core of system (3), $M_{10}, M_{20}$ will satisfy the following equations, respectively:

$$
\begin{aligned}
& \beta_{1} Q_{1}-d_{1} Q_{1}^{2}+\left[\theta_{2}\right]_{\alpha} Q_{2}=0, \\
& \beta_{2} Q_{2}-d_{2} Q_{2}^{2}+\left[\theta_{1}\right]_{\alpha} Q_{1}=0 .
\end{aligned}
$$

Consequently, $M_{10} M_{20} \times \operatorname{Tr} A=-\left(\left[\theta_{1}\right]_{\alpha} M_{10}^{2}+\left[\theta_{2}\right]_{\alpha} M_{20}^{2}\right)$, and then $\operatorname{Tr} A<0$.

From (55), we can learn that

$$
\begin{aligned}
& {\left[\theta_{1}\right]_{\alpha}=-\frac{\left(\beta_{2} M_{20}-d_{2} M_{20}^{2}\right)}{M_{10}},} \\
& {\left[\theta_{2}\right]_{\alpha}=-\frac{\left(\beta_{1} M_{10}-d_{1} M_{10}^{2}\right)}{M_{20}} .}
\end{aligned}
$$


Therefore,

$$
\begin{aligned}
\operatorname{det} A= & \left(\beta_{1}-2 d_{1} M_{10}\right)\left(\beta_{2}-2 d_{2} M_{20}\right)-\left[\theta_{1}\right]_{\alpha}\left[\theta_{2}\right]_{\alpha} \\
= & \left(\beta_{1}-2 d_{1} M_{10}\right)\left(\beta_{2}-2 d_{2} M_{20}\right) \\
& -\left(\beta_{1}-d_{1} M_{10}\right)\left(\beta_{2}-d_{2} M_{20}\right) .
\end{aligned}
$$

From (56) we can conclude that $\beta_{i}-d_{i} M_{i 0}<0$ and det $A>$ 0 . As far as $(\operatorname{Tr} A)^{2}-4$, $\operatorname{det} A>0$ clearly comes into existence. Therefore, the equilibrium core $M\left(M_{10}, M_{20}\right)$ is stable. Consequently, the equilibrium core $M\left(M_{10}, M_{20}\right)$ is stable in $R_{+}^{2}$. This completes the proof.

Accordingly, the members of the two colonies will trend their maximum eventually and maintain stability if satisfying certain conditions whether there are members shifting from one colony into another or not.

3.3. Stability Analysis on Innovation Diffusion. Since the equilibrium core in system (3) is stable and we are interested in the asymptotic behavior of system (6), we only discuss the stability of system (6) on the base of system (3) in it's equilibrium core. That is to say, we only discuss the stability of innovation diffusion when the members of the two colonies are in their stability. Suppose that the global equilibrium core of system (3) is $\left(M_{10}, M_{20}\right)$, and $Q_{10}=M_{10}, Q_{20}=M_{20}$. At the same time suppose $\beta_{1}=a_{1}-b_{1} M_{10}+d_{11} M_{10}+\beta_{11}+e_{1}$, $\beta_{2}=a_{2}-b_{2} M_{20}+d_{21} M_{20}+\beta_{21}+e_{2}$, then we have the following theorem.

Theorem 8. Systems

$$
\begin{aligned}
& \left(\begin{array}{l}
\dot{N}_{1 \alpha} \\
\dot{N}_{2 \alpha}
\end{array}\right) \\
& \epsilon\left(\begin{array}{l}
a_{1} M_{10}-\left(\beta_{1}+\left[\theta_{1}\right]_{\alpha}\right) N_{1 \alpha}-b_{1} N_{1 \alpha}^{2}+k_{2}\left[\theta_{2}\right]_{\alpha} N_{2 \alpha} \\
a_{2} M_{20}-\left(\beta_{2}+\left[\theta_{2}\right]_{\alpha}\right) N_{2 \alpha}-b_{2} N_{2 \alpha}^{2}+k_{1}\left[\theta_{1}\right]_{\alpha} N_{1 \alpha}
\end{array}\right)
\end{aligned}
$$

have one and only one positive equilibrium core, which is stable in $R_{+}^{2}$.

Proof. If $\left[\theta_{1}\right]_{\alpha}=\left[\theta_{2}\right]_{\alpha}=0$, system (58) has a unique positive equilibrium core $\left(C_{1}, C_{2}\right)$, where $C_{i}=\left(-\beta_{i}+\right.$ $\left.\sqrt{\beta_{i}^{2}+4 d_{i} a_{i} M_{i 0}}\right) / 2 d_{i}$. Obviously, this equilibrium core is stable in $R_{+}^{2}$; that is to say, if there is no shifting between two colonies, this innovation will occupy its potential eventually and remain stable.

If $\left[\theta_{1}\right]_{\alpha}=0,\left[\theta_{2}\right]_{\alpha}>0$, system (58) can be reduced as

$$
\left(\begin{array}{c}
\dot{N}_{1 \alpha} \\
\dot{N}_{2 \alpha}
\end{array}\right) \in\left(\begin{array}{c}
a_{1} M_{10}-\beta_{1} N_{1 \alpha}-b_{1} N_{1 \alpha}^{2}+k_{2}\left[\theta_{2}\right]_{\alpha} N_{2 \alpha} \\
a_{2} M_{20}-\left(\beta_{2}+\left[\theta_{2}\right]_{\alpha}\right) N_{2}-b_{2} N_{2 \alpha}^{2}
\end{array}\right)
$$

Take the second equation of system (6) into consideration. $C_{2}$ is the unique globe equilibrium core of this equation in $R_{+}^{2}$, where

$$
C_{2}=\frac{-\left(\beta_{2}+\left[\theta_{2}\right]_{\alpha}\right)+\sqrt{\left(\beta_{2}+\left[\theta_{2}\right]_{\alpha}\right)^{2}+4 b_{2} a_{2} M_{20}}}{2 b_{2}} .
$$

Assume that $C_{1}$ is the positive solution of the following equation:

$$
a_{1} M_{10}-\beta_{1} N_{1}-b_{1} N_{1}^{2}+k_{2}\left[\theta_{2}\right]_{\alpha} C_{2}=0,
$$

then follow

$$
C_{1}=\frac{-\beta_{1}+\sqrt{\beta_{1}^{2}+4 b_{1}\left(a_{1} M_{10}+k_{2}\left[\theta_{2}\right]_{\alpha} C_{2}\right)}}{2 b_{1}} .
$$

Define $N_{i 0}=N_{i}-C_{i},(i=1,2)$, then system (59) can be rewritten as

$$
\left(\begin{array}{c}
\dot{N}_{10 \alpha} \\
\dot{N}_{10 \alpha}
\end{array}\right) \in\left(\begin{array}{c}
a_{1} M_{10}-\beta_{1}\left(N_{10 \alpha}+C_{1}\right)-b_{1}\left(N_{10 \alpha}+C_{1}\right)^{2}+k_{2}\left[\theta_{2}\right]_{\alpha}\left(N_{20 \alpha}+C_{2}\right) \\
a_{2} M_{20}-\left(\beta_{2}+\left[\theta_{2}\right]_{\alpha}\right)\left(N_{20 \alpha}+C_{2}\right)-b_{2}\left(N_{20 \alpha}+C_{2}\right)^{2}
\end{array}\right) .
$$

The coefficient matrix of the linear system of system (63) is

A

$$
=\left[\begin{array}{cc}
-\left(\beta_{1}+2 b_{1}\left(N_{10}+C_{1}\right)\right) & k_{2} \theta_{2} \\
0 & -\left(\beta_{2}+\theta_{2}+2 b_{2}\left(N_{20}+C_{2}\right)\right)
\end{array}\right] .
$$

Since the feature values of $A$ are both less than 0 , the equilibrium core $\left(C_{1}, C_{2}\right)$ is stable. So this equilibrium core is stable in $R_{+}^{2}$.

If $\left[\theta_{1}\right]_{\alpha}>0,\left[\theta_{2}\right]_{\alpha}>0$, the demonstration process is similar to the process of Theorem 4 . We can conclude that there exits a unique positive equilibrium core $\left(C_{1}, C_{2}\right)$ and the equilibrium core is stable. Consequently, the innovation will reach its maximal potential and keep stable. This completes the proof.

\section{The Empirical Analysis}

Owing to the household management system of planned economy in history, China has divided the population into urban population and rural population. Owing to the strict control, rare shifting, huge gaps between industry and agriculture, and the different environment and living level, there exists great difference between urban population and rural population in communication channels, information spreading, and consumption habit. However, with the reform and exposure to the outside world, the economic development converts China into urban society from village society, and 
the inhabitants begin to move. According to the related news, there is $1 \%$ rural population moving into town per year since the 1980s. The ratio between urban population and rural population may be $7: 3$ after 60 years. Thus, it is not enough to discuss their consumption systems, respectively, without taking the population moving between the cities and countries into consideration. Based on this, we will try to build the dynamical model for telephone diffusion under the condition of the existing large population moving between town and country.

To make it easier, we suppose that this model satisfies following hypotheses:

(1) since the standard of living in town is superior to that in the country of China, we suppose $\theta_{2}=0$, which indicates that there are no people in China shifting from town into country;

(2) since the communication by telephone is popular and necessary, we suppose $k_{1}=1, e_{i}=0$ which indicates that the telephone users in country will continue using it after shifting into town and users in town will not give up using it;

(3) the population in China will reach 1.6 billion and maintain stable, which is obtained according to some related research on population in China [28].

4.1. Model Conversion. In this section, we first use the definition of subduction defined by Zadeh, which means $u-$ $v=\left(u_{1}-v_{2}, u_{2}-v_{1}\right)$, in which $u=\left(u_{1}, u_{2}\right), v=\left(v_{1}, v_{2}\right) \in D^{n}$. And then we use the $H$-difference to simulate the diffusion process of local telephone in China.

According to the hypothesis defined above, system (58) can be rewritten as

$$
\begin{gathered}
\dot{\widetilde{N}}_{1}=a_{1} \widetilde{A}_{1}+b_{1} \widetilde{N}_{1}-c_{1} \widetilde{N}_{1}^{2}+d_{1} \widetilde{N}_{2}, \\
\dot{\widetilde{N}}_{2}=a_{2} \widetilde{A}_{2}+b_{2} \widetilde{N}_{2}-c_{2} \widetilde{N}_{2}^{2} .
\end{gathered}
$$

According to the definition of subduction defined by article [29], system (65) can be rewritten as

$$
\begin{gathered}
\underline{N}_{1}(t+1)-\underline{N}_{1}(t)=a_{1} \underline{A}_{1}+b_{1} \underline{N}_{1}(t)-c_{1} \bar{N}_{1}^{2}(t)+\underline{d}_{1} \underline{N}_{2}(t), \\
\bar{N}_{1}(t+1)-\bar{N}_{1}(t)=a_{1} \bar{A}_{1}+b_{1} \bar{N}_{1}(t)-c_{1} \underline{N}_{1}^{2}(t)+\bar{d}_{1} \bar{N}_{2}(t), \\
\underline{N}_{2}(t+1)-\underline{N}_{2}(t)=a_{2} \underline{A}_{2}+b_{2} \underline{N}_{2}(t)-c_{2} \bar{N}_{2}^{2}(t), \\
\bar{N}_{2}(t+1)-\bar{N}_{2}(t)=a_{2} \bar{A}_{2}+b_{2} \bar{N}_{2}(t)-c_{2} \underline{N}_{2}^{2}(t) .
\end{gathered}
$$

\begin{tabular}{|c|c|c|}
\hline Year & $\begin{array}{c}\text { Number of } \\
\text { telephone } \\
\text { subscribers in town }\end{array}$ & $\begin{array}{l}\text { Number of telephone } \\
\text { subscribers in country }\end{array}$ \\
\hline 1989 & 439.62 & 128.42 \\
\hline 1990 & 538.45 & 146.58 \\
\hline 1991 & 670.83 & 174.23 \\
\hline 1992 & 920.57 & 226.34 \\
\hline 1993 & 1407.37 & 325.79 \\
\hline 1994 & 2246.78 & 482.75 \\
\hline 1995 & 3263.56 & 807 \\
\hline 1996 & 4277.82 & 1216.92 \\
\hline 1997 & 5244.4 & 1786.63 \\
\hline 1998 & 6259.81 & 2482.28 \\
\hline 1999 & 7463.3 & 3408.4 \\
\hline 2000 & 9311.6 & 5171.3 \\
\hline 2001 & 11193.7 & 6843.1 \\
\hline 2002 & 13579.1 & 7843.1 \\
\hline 2003 & 17109.7 & 9165.0 \\
\hline 2004 & 21025.1 & 10150.5 \\
\hline 2005 & 23975.3 & 11069.2 \\
\hline 2006 & 25132.9 & 11645.6 \\
\hline 2007 & 24859.4 & 11685.5 \\
\hline 2008 & 23151.5 & 10827.4 \\
\hline 2009 & 20742.8 & 10432.8 \\
\hline 2010 & 19671.0 & 9769.5 \\
\hline 2011 & 18993.3 & 9477.3 \\
\hline
\end{tabular}

That is,

$$
\begin{gathered}
\underline{N}_{1}(t+1)=a_{1} \underline{A}_{1}+\left(1+b_{1}\right) \underline{N}_{1}(t)-c_{1} \bar{N}_{1}^{2}(t)+\underline{d}_{1} \underline{N}_{2}(t), \\
\bar{N}_{1}(t+1)=a_{1} \bar{A}_{1}+\left(1+b_{1}\right) \bar{N}_{1}(t)-c_{1} \underline{N}_{1}^{2}(t)+\bar{d}_{1} \bar{N}_{2}(t), \\
\underline{N}_{2}(t+1)=a_{2} \underline{A}_{2}+\left(1+b_{2}\right) \underline{N}_{2}(t)-c_{2} \bar{N}_{2}^{2}(t) \\
\bar{N}_{2}(t+1)=a_{2} \bar{A}_{2}+\left(1+b_{2}\right) \bar{N}_{2}(t)-c_{2} \underline{N}_{2}^{2}(t)
\end{gathered}
$$

TABLE 2: The data of telephone subscribers in the year 1989-2011.

Then we used Genetic Algorithms (GA) to model the coefficient of model (67), which were shown in Table 4, where error is the permitted maximum error ratio between the data predicted by model and history data.

If we take the coefficient value as shown in Table 2 to the minimum of the target values in Table 3 , the plots of potential curve of telephone in urban area or in rural area governed by model (67) are shown in Figure 3 or Figure 4, respectively.

In Figure 3, the red line is made up of history data and the green solid line and the green dot line represent the upper limit and the lower limit of the telephone consumers in urban area, respectively.

In Figure 4, the red line is made up of history data and the blue solid line and the blue dot line represent the upper limit and the lower limit of the telephone consumers in rural area, respectively.

From Figures 3 and 4, the fuzzy simulation effect is not perfect, and the fuzzy intervals of the consumer numbers are too big to predict the diffusion process of innovation. We could only find the time of inflection point and the maximal potential market from Figures 3 and 4 . So we try to use the definition of Hukuhara difference, which, $u-v=(\underline{u}(\alpha)-$ $\underline{v}(\alpha), \bar{u}(\alpha)-\bar{v}(\alpha))$, comes into exist. Consequently, we have the following system: 


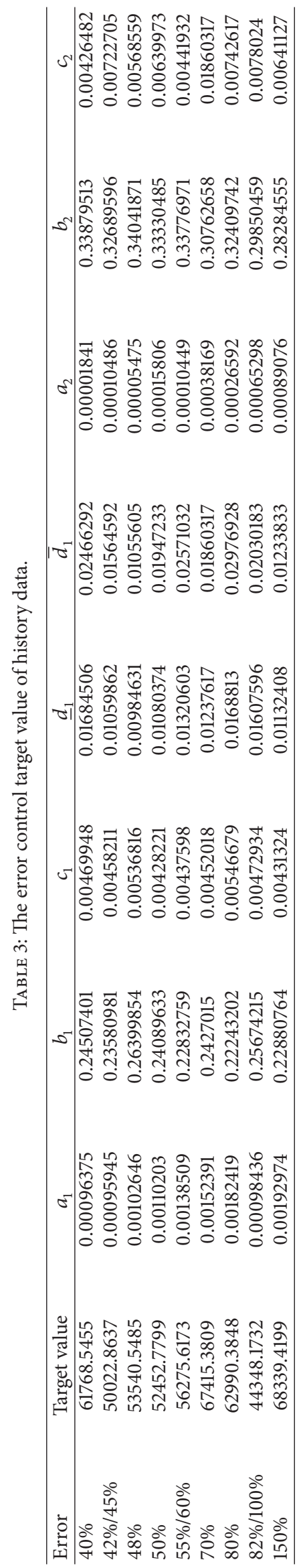




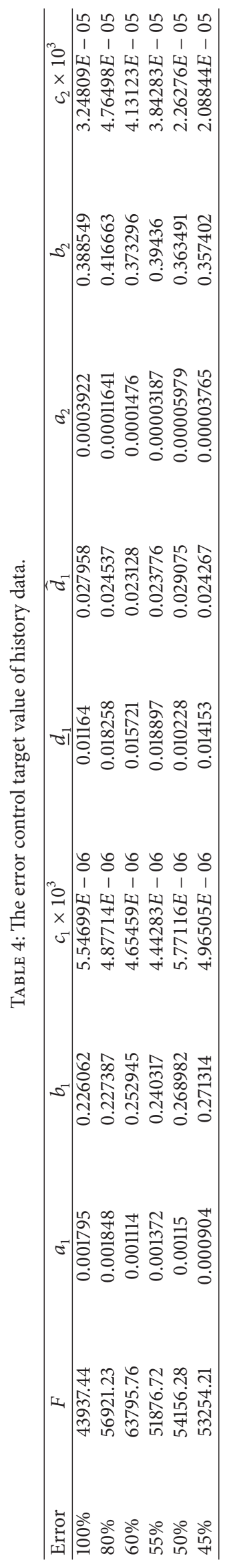




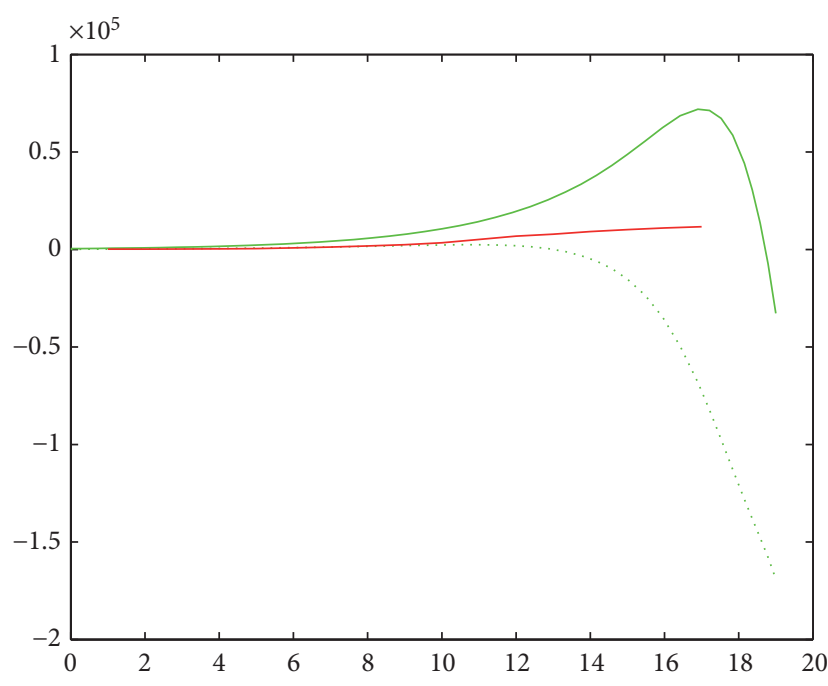

FIgURE 3: Plots of potential curve of telephone in urban area governed by model (67).

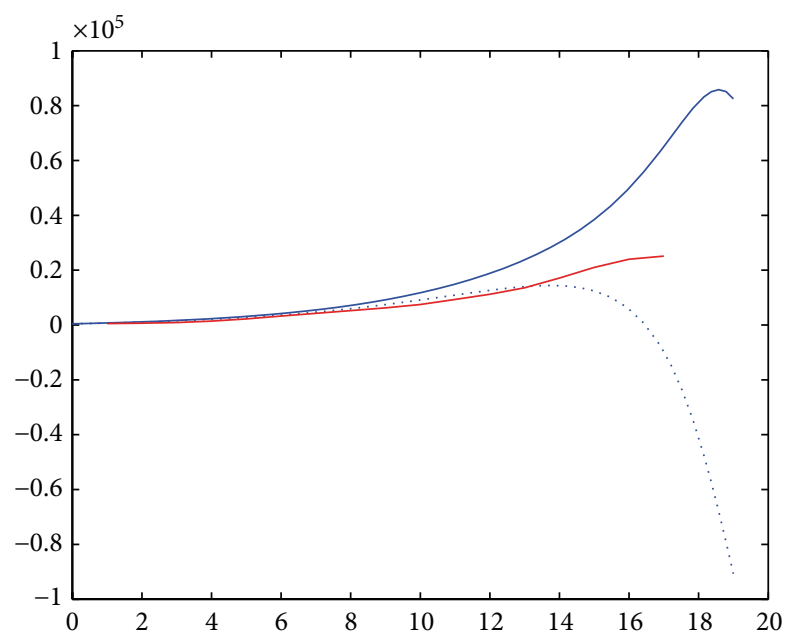

FIGURE 4: Plots of potential curve of telephone in rural area governed by model (67).

$$
\begin{gathered}
\underline{N}_{1}(t+1)=a_{1} \underline{A}_{1}+\left(1+b_{1}\right) \underline{N}_{1}(t)-c_{1} \underline{N}_{1}^{2}(t)+\underline{d}_{1} \underline{N}_{2}(t), \\
\bar{N}_{1}(t+1)=a_{1} \bar{A}_{1}+\left(1+b_{1}\right) \bar{N}_{1}(t)-c_{1} \bar{N}_{1}^{2}(t)+\bar{d}_{1} \bar{N}_{2}(t), \\
\underline{N}_{2}(t+1)=a_{2} \underline{A}_{2}+\left(1+b_{2}\right) \underline{N}_{2}(t)-c_{2} \underline{N}_{2}^{2}(t), \\
\bar{N}_{2}(t+1)=a_{2} \bar{A}_{2}+\left(1+b_{2}\right) \bar{N}_{2}(t)-c_{2} \bar{N}_{2}^{2}(t) .
\end{gathered}
$$

We give the predicted figures in Figures 5, 6, and 7, respectively, in which the error control ratios are $45 \%, 50 \%$, and $100 \%$, respectively.

Since the the effect of simulation under other control simulation error ratio is not good, we only give the potential market of local telephone under the control simulation error ratio which is $45 \%, 50 \%$, and $100 \%$, respectively. From Table 5 , the number of local telephone consumers in China ranges

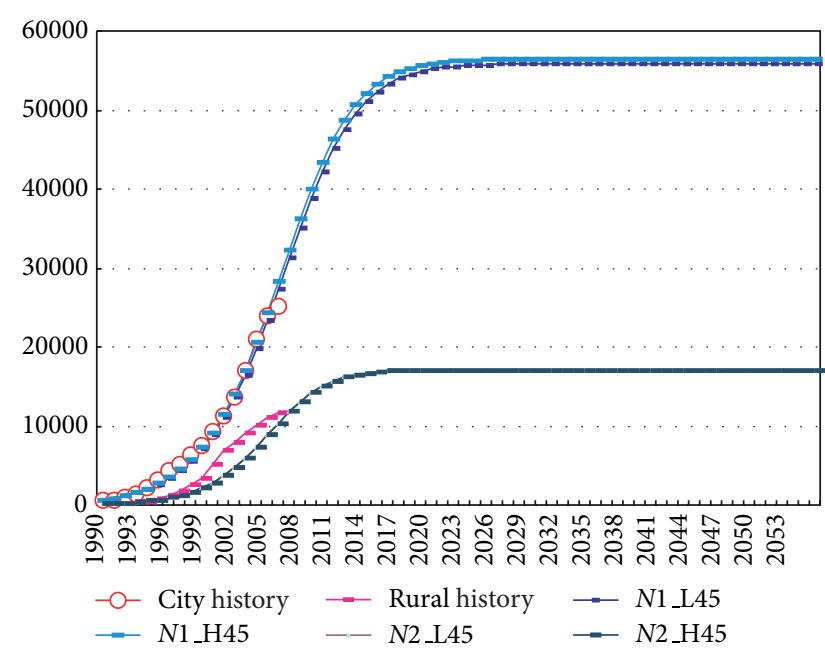

FIgURE 5: Plots of potential curve of telephone in urban area and rural area governed by model (68) (the control error rate is $45 \%$ ).

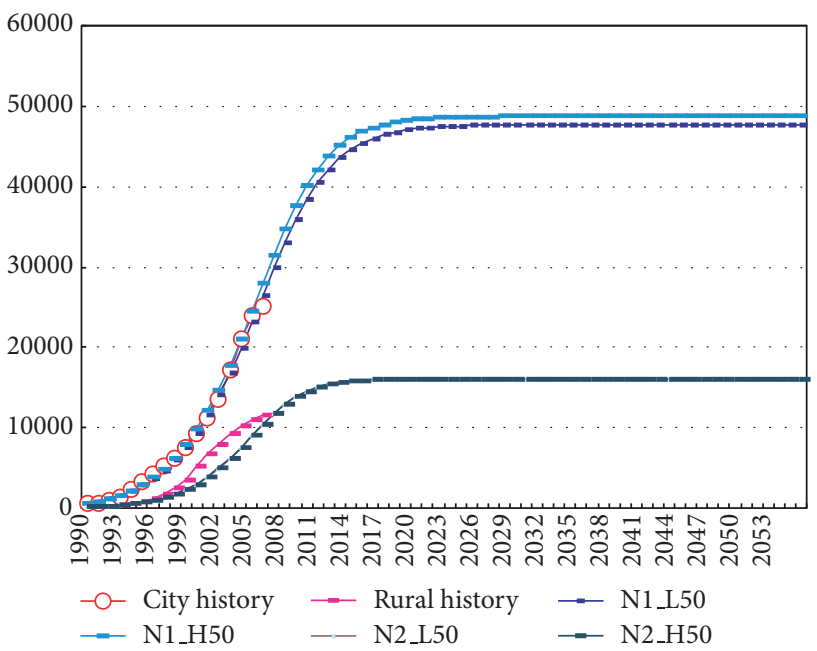

FIgURE 6: Plots of potential curve of telephone in urban area and rural area governed by model (68) (the control error rate is $50 \%$ ).

from 54203.57 to 73615.08 in respect to different control error ratios.

4.2. Contrastive Analysis. In this section, firstly we consider the cases of system (58) without any fuzzy coefficients, then take the Bass model to simulate the process of local telephone diffusion in China.

We also suppose that this model satisfies the following hypotheses:

(1) since the standard of living in town is superior to that of country areas in China, we suppose $\theta_{2}=0$, $\theta_{1}=1 \%$, which means that the population shifting from the country into the town is $1 \%$ of rural area inhabitants at that time while there are no people in China shifting from the town into the country; 
TABLE 5: The predicted consumer numbers of China local telephone under different control simulation errors.

\begin{tabular}{lcccc}
\hline Error & $\begin{array}{c}\text { The minimum value } \\
\text { of urban area }\end{array}$ & $\begin{array}{c}\text { The maximum value } \\
\text { of urban area }\end{array}$ & $\begin{array}{c}\text { The minimum value } \\
\text { of rural area }\end{array}$ & $\begin{array}{c}\text { The maximum value } \\
\text { of rural area }\end{array}$ \\
\hline $100 \%$ & 42194.89787 & 43026.2 & 12008.67 & 12012.68 \\
$50 \%$ & 47665.11832 & 48739.22 & 16071.58 & 16072.23 \\
$45 \%$ & 55876.63922 & 56496.48 & 17118.18 & 17118.6 \\
\hline
\end{tabular}

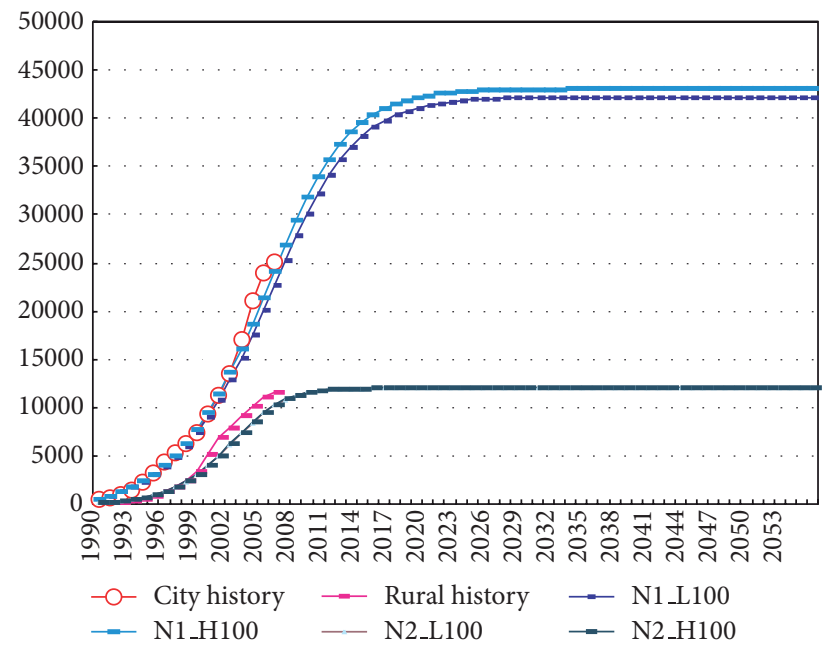

Figure 7: Plots of potential curve of telephone in urban area and rural area governed by model (68) (the control error rate is $100 \%$ ).

(2) since communication by telephone is popular and necessary, we suppose $k_{1}=1$, which indicates that the telephone users in the country will continue using it after shifting into town and users in town will not give up using it;

(3) the population in China will reach 1.6 billion and maintain stability, according to data obtained from some related research on population in China.

Based on the hypotheses above, we can conclude that the population of the country will be stable in 0.48 billion and that of the town will be 1.12 billion, which is concluded by the nonlinear regression on system (3) without any fuzzy coefficients. According to the 14 groups of historical data, and the software SPSS11.0, we also make nonlinear regression on system (58) and obtain the following model:

$$
\begin{gathered}
\dot{N}_{1}=88.8608+0.21945 N_{1}-5.9986 \times 10^{-6} N_{1}^{2}+0.01 N_{2}, \\
\dot{N}_{2}=0.4800+0.39966 N_{2}-3.0032 \times 10^{-5} N_{2}^{2} .
\end{gathered}
$$

In which the coefficient of external influence in town $a_{1}=0.0007934$, the coefficient of the internal influence $b_{1}=$ 0.22536 , and those in the country, respectively, are 0.00001 and 0.399696 . With the calculation on the system (59), the market potential of telephone users in the town is 375684000 and that in country is 133090000 . The $R$ squared of the first equation of (69) is 0.95748 and that of the second is 0.91051 .

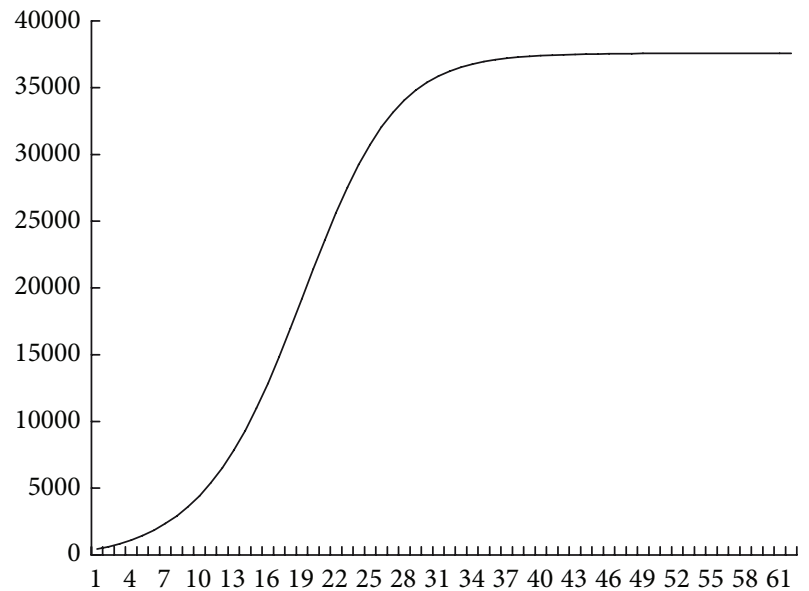

FIGURE 8: Plot of the diffusion of telephone users in urban area of China governed by model (69).

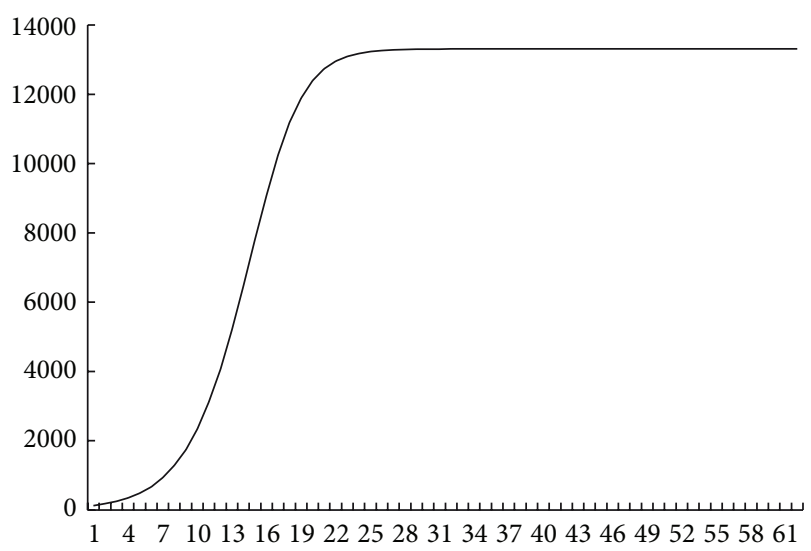

FIgURE 9: Plot of the diffusion of telephone users in rural area of China governed by model (69).

We use the software Mathematic 4 to forecast the numbers of telephone users in the town and the country, which are shown in Figures 8 and 9, respectively. And the origin point in these figures denotes the year 1989.

Consequently, we arrive at the following conclusions.

(1) When the population of the town and that of the country trend to stability, the users among them also trend to stability, the number of which is 13309000 and 375684000 , respectively.

(2) Since the medium system in town is highly superior to that in the rural areas, the necessity and popularity of 
communication in town are also better than those in the rural area and the coefficient of external affection in town (0.0007934) is obviously larger than that in rural area (0.00001).

(3) The coefficient of internal affection in town (0.22536) is much less than that in the rural area (0.3399696), which means that the inhabitants of the rural area are more reliable on oral communication than those in town. The main reason is that there are few communication channels in the rural area and the communication information mainly depends on oral communication. However, the network of communication in town is much developed and the necessity of oral communication is not so necessary.

(4) The population of telephone users in town will reach its maximal market potential in about 30 years, while in rural area it will be in about 15 years later. In fact, this dose not mean that the diffusion rate in rural area is faster than that in town. In fact, the diffusion rate in town is much faster than that in rural area. The main reason for this is that the market potential in town (375684000) is much higher than that in rural area (133090000).

We also use Bass model to describe and forecast the numbers of the telephone users in the town or in rural areas, respectively, without taking the people shifting between them into account. With the nonlinear regression, another forecasting model is governed by

$$
\begin{aligned}
\dot{N}_{1}= & \left(0.000313699+3.61914 \times 10^{-6} N_{1}\right) \\
& \times\left(64443.178967-N_{1}\right), \\
\dot{N}_{2}= & 3.1750 \times 10^{-5} N_{2}\left(13446.495087-N_{2}\right)
\end{aligned}
$$

in which the coefficient of external affection in town $a_{1}=$ 0.000313699 , the coefficient of the internal affection $b_{1}=$ 0.233073 , and those in rural area, respectively, are 0 and 0.42672 . The market potential of telephone users in town is 644431789 and that in rural area is 134464950 . The $R$ squared of the first equation of (70) is 0.94766 and that of the second is 0.9047 .

Furthermore, we also use the Bass model to describe and forecast the number of the telephone users without considering where the users are from. The model is as follows:

$$
\begin{aligned}
\dot{N}= & \left(0.000412046+3.70996 \times 10^{-6} N\right) \\
& \times(71216.171268-N) .
\end{aligned}
$$

The market potential of telephone users in China is 712161700 and the prediction curve of this model is shown in Figure 10. The origin points in these figures denote the year 1989.

Comparing model (71) with model (70) we can see that if we distinguish where people settle down, the total market potential of telephone users in China will be 778896700 or, if not considering the place of setting, it will be 712161700 . That is to say, there will be another 66 million in the market potential of China if distinguishing where people settle down.

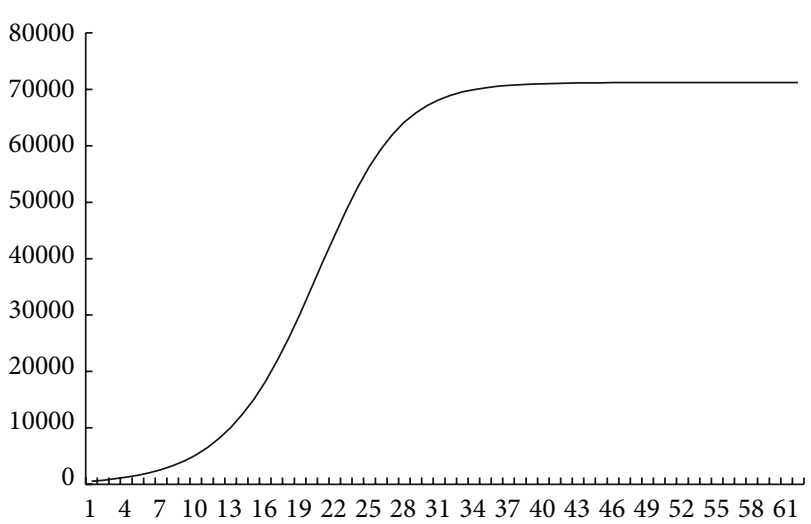

FIgUre 10: Plot of the diffusion curve of telephone in China governed by model (71).

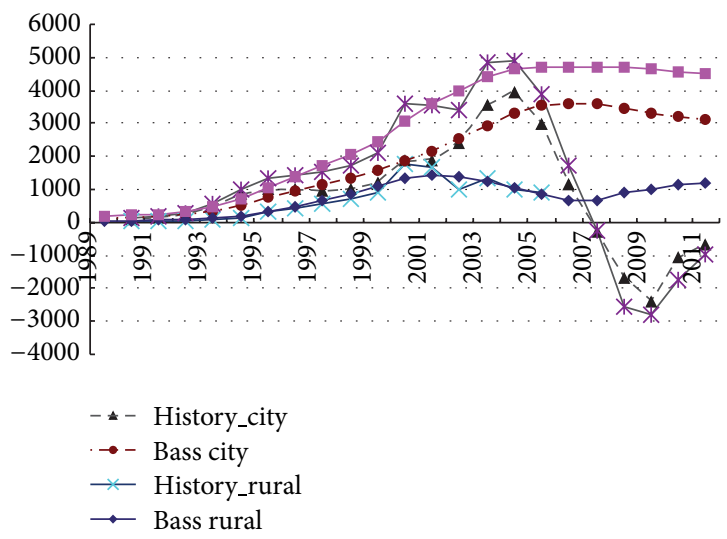

FIGURE 11: Plots of the diffusion rate of telephone by Bass model.

In order to distinguish which prediction model is more accurate, we have drawn the plots of the prediction curves of different models and compared them with those of the historical data, which are shown in Figures 11, 12, and 13 , respectively. $y_{\_} u, y_{-} c, y_{-} a$ denote the diffusion rate of telephones in town, in the rural area, or the total in China, respectively, and $p_{-} y u, p_{-} y c, y_{-} y a$ denote the prediction numbers of those, respectively, by Bass model. p_c_me, p_u_me denote the prediction numbers of the diffusion rate of telephones in town or in the rural area by model (69). From Figure 11, there is no difference in accuracy between model (70) and model (71). However, the prediction numbers of model (69) are more accurate than those of model (70), as deduced by Figures 12 and 13.

We also drew the prediction curves of telephone users in town and in rural areas governed by model (69) or model (70), which are shown in Figures 15 and 14, respectively. The curves are almost identical in Figure 15, which means that the potential of telephone usage in rural areas is virtually the same whether governed by model (69) or model (70) at any given point time $t$, while there is a wide difference between those in town, as shown in Figure 14. With the course of China's stepping into an urban society from a rural society, 


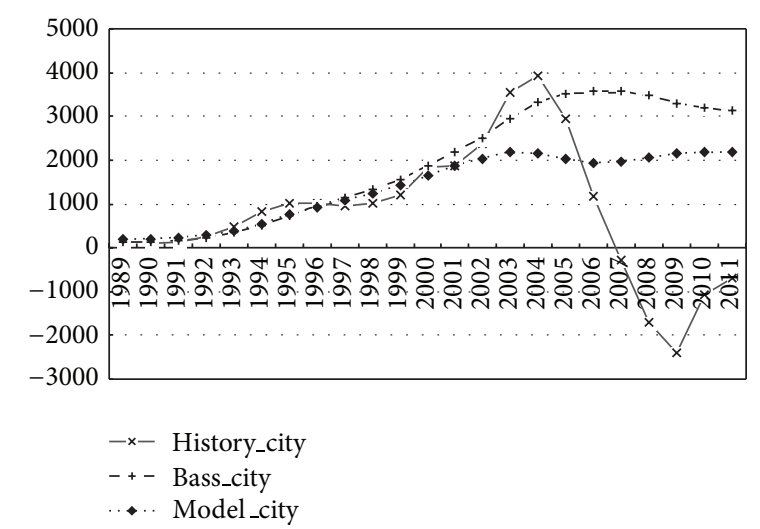

FIGURE 12: Plots of the diffusion rate of telephone in urban area by model (69) or model (70).

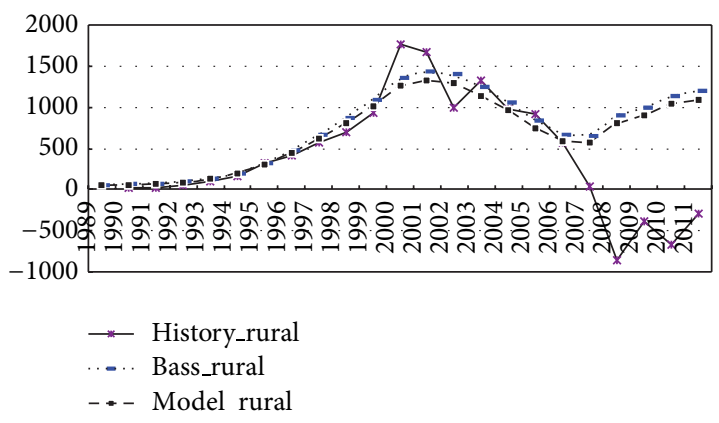

FIGURE 13: Plots of the diffusion rate of telephone in rural area by model (69) or model (70).

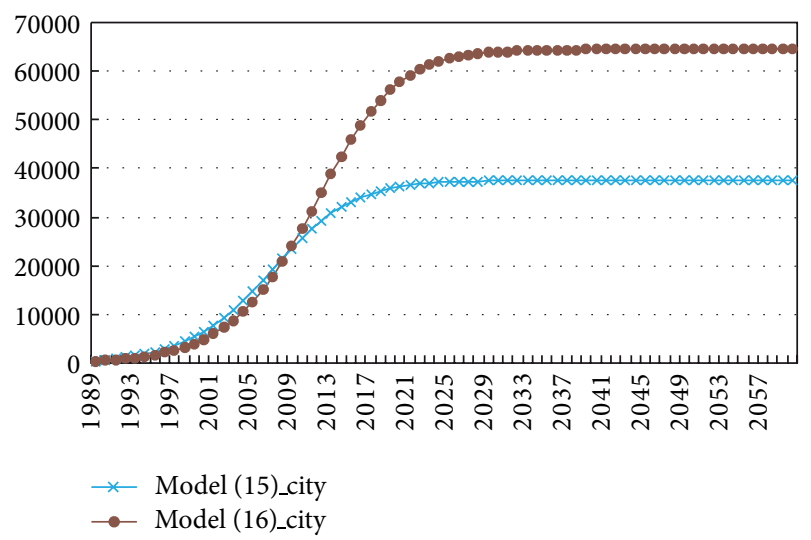

FIGURE 14: Plots of potential curve of telephone in urban area governed by model (69) or model (70).

more people are moving into town from rural areas and have a stronger ability and demand for communication. So the potential predicted by model (69) should be bigger than that predicted by model (70). However, on the contrary, the potential predicted by model (69) is much smaller than that predicted by model (70) as shown in Figure 14.

The cause may be that the Bass model uses historical data to predict the market potential, and the historical data of

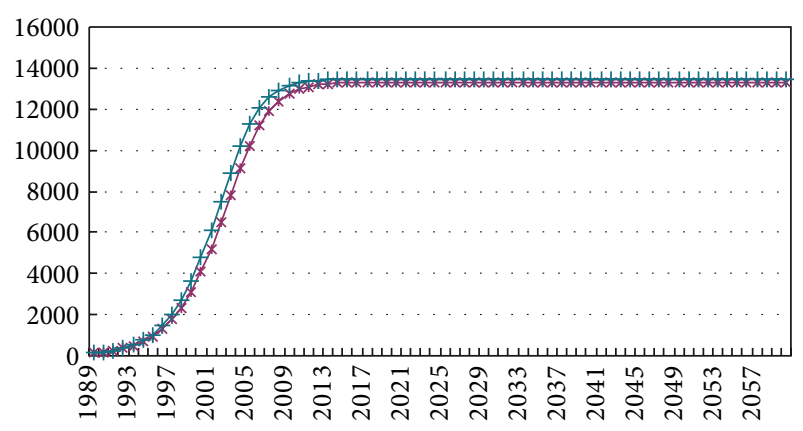

* Model (15)_rural
+ Model (16)_rural

FIgURE 15: Plots of potential curve of telephone in rural area governed by model (69) or model (70).

towns have involved those who have shifted from rural areas. So the Bass model magnifies the potential of innovation in town.

\section{Conclusion}

In this paper, we constructed an innovation diffusion model with migration between two different colonies. With the analysis of the innovation diffusion model based on the members of the two colonies shifting between each other, and on the empirical analysis on the telephone users of China, we conclude that the subscribers will trend to their maximal market potential whether or not there are members shifting between town and rural areas. During the process of urbanization and the relaxation of household management in China, such phenomena should not be ignored since its influence on the economic and social system may be vital and significant. Since obtaining data is very difficult, the population data is directly obtained from related information and empirical estimation. Moreover, the proposed model is acceptable without competing technologies taken into consideration. The simulation of data is not accurate enough since we have not taken the economic environment, 
competing technologies, and the effect of decreasing costs in communication into consideration, all of which will be included in future research.

\section{Acknowledgments}

This research was supported by the Key Program of NSFC (Grant no. 70831005) and the National Science Foundation for Distinguished Young Scholars, China (Grant no. 70425005).

\section{References}

[1] G. S. Day, P. J. H. schoemaker, and R. E. Gunther, Wharton on Managing Emerging Technologies, John Wiley \& Sons, New York, NY, USA, 2000.

[2] A. Prasad and V. Mahajan, "How many pirates should a software firm tolerate? An analysis of piracy protection on the diffusion of software," International Journal of Research in Marketing, vol. 20, no. 4, pp. 337-353, 2003.

[3] F. M. Bass, "A new product growth for model consumer durables," Management Science, vol. 50, no. 5, pp. 215-227, 1969.

[4] B. Kang, H. Kim, C. Han, and C. Yim, "A demand-based model for forecasting innovation diffusion," Computers and Industrial Engineering, vol. 30, no. 3, pp. 487-499, 1996.

[5] C. H. Cheng, Y. S. Chen, and Y. L. Wu, "Forecasting innovation diffusion of products using trend-weighted fuzzy time-series model," Expert Systems with Applications, vol. 36, no. 2, pp. 1826-1832, 2009.

[6] D. B. Jun, S. K. kim, Y. S. Park, M. H. Park, and A. R. Wilson, "Forecasting telecommunication service subscribers in substitutive and competitive environments," International Journal of Forecasting, vol. 18, no. 4, pp. 561-581, 2002.

[7] E. Montaguti, S. Kuester, and T. S. Robertson, "Entry strategy for radical product innovations: a conceptual model and propositional inventory," International Journal of Research in Marketing, vol. 19, no. 1, pp. 21-42, 2002.

[8] L. A. Fourt and J. W. Woodlock, "Early prediction of market success for new grocery products," Journal of Marketing, vol. 25, no. 2, pp. 31-38, 1960.

[9] H. Gruber, "Competition and innovation. The diffusion of mobile telecommunications in Central and Eastern Europe," Information Economics and Policy, vol. 13, no. 1, pp. 19-34, 2001.

[10] J. T. C. Teng, V. Grover, and W. Güttler, "Information technology innovations: general diffusion patterns and its relationships to innovation characteristics," IEEE Transactions on Engineering Management, vol. 49, no. 1, pp. 13-27, 2002.

[11] S. Kalish, "A new product adoption model with price, advertising, and uncertainty," Management Science, vol. 31, no. 12, pp. 1569-1585, 1985.

[12] E. Mansfield, "Technical change and the rate of imitation," Econometrica, vol. 29, pp. 741-766, 1961.

[13] V. Mahajan and A. Peterson, "Innovation diffusion in a dynamic potential adopter population," Management Science, vol. 24, no. 15, pp. 1589-1597, 1978.

[14] V. Mahajan, E. Mller, and F. Bass, "New product diffusion models in marketing: a review and directions for research," Journal of Marketing, vol. 54, no. 1, pp. 1-26, 1990.

[15] M. Möhle, "The coalescent in population models with timeinhomogeneous environment," Stochastic Processes and their Applications, vol. 97, no. 2, pp. 199-227, 2002.
[16] P. R. Steffens, "A model of multiple-unit ownership as a diffusion process," Technological Forecasting and Social Change, vol. 70, no. 9, pp. 901-917, 2003.

[17] C. Michalakelis, D. Varoutas, and T. Sphicopoulos, "Innovation diffusion with generation substitution effects," Technological Forecasting and Social Change, vol. 77, no. 4, pp. 541-557, 2010.

[18] F. H. Clarke, N. Darrough, and J. Heineke, "Optimal pricing policy in the presence of experience effects," Journal of Business, vol. 55, no. 4, pp. 517-530, 1982.

[19] J. A. Dodson and E. Muller, "Models of new product diffusion through advertising and words of mouth," Manangement Science, vol. 24, no. 15, pp. 1568-1578, 1978.

[20] D. C. Jain and R. C. Rao, "Effect of price on the demand for durables: modeling, estimation and finding," International Journal of Forecasting, vol. 8, no. 2, pp. 163-170, 1990.

[21] S. Kalish, "Monopolist pricing with dynamic demand and production cost," Marketing Science, vol. 2, no. 2, pp. 135-159, 1983.

[22] P. K. Kapur, O. Singh, U. Chanda, and M. Basirzadeh, "Determining adoption pattern with pricing using two-dimensional innovation diffusion model," Journal of High Technology Management Research, vol. 21, no. 2, pp. 136-146, 2010.

[23] R. Peres, E. Muller, and V. Mahajan, "Innovation diffusion and new product growth models: a critical review and research directions," International Journal of Research in Marketing, vol. 27, no. 2, pp. 91-106, 2010.

[24] B. Robinson and C. Lakhani, "Dynamic Price models for new product planning," Management Science, vol. 21, no. 10, pp. 1113$1122,1975$.

[25] W. Wendi, P. Fergola, and C. Tenneriello, "Innovation diffusion model in patch environment," Applied Mathematics and Computation, vol. 134, no. 1, pp. 51-67, 2003.

[26] P. Diamond, "Stability and periodicity in fuzzy differential equations," IEEE Transactions on Fuzzy Systems, vol. 8, no. 5, pp. 583-590, 2000.

[27] C. V. Negoiță and D. A. Ralescu, Applications of Fuzzy Sets to Systems Analysis, John Wiley \& Sons, New York, NY, USA, 1975.

[28] C. Yunjie and Z. Yan, "The population target in our country: no more than 1.6 billion before middle of this century [EB/OL]," http://news.xinhuanet.com/newscenter/2003-01/08/ content_683703.htm.

[29] J. Xu, Z. Liao, and Z. Hu, "A class of linear differential dynamical systems with fuzzy initial condition," Fuzzy Sets and Systems, vol. 158, no. 21, pp. 2339-2358, 2007. 


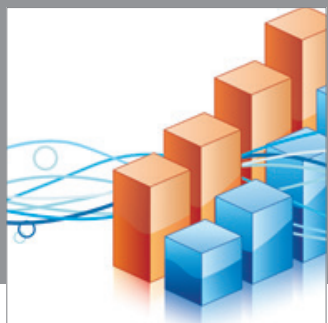

Advances in

Operations Research

mansans

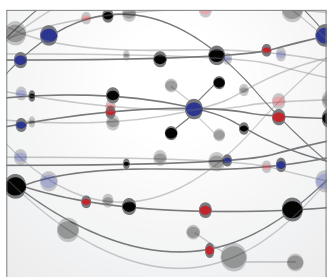

The Scientific World Journal
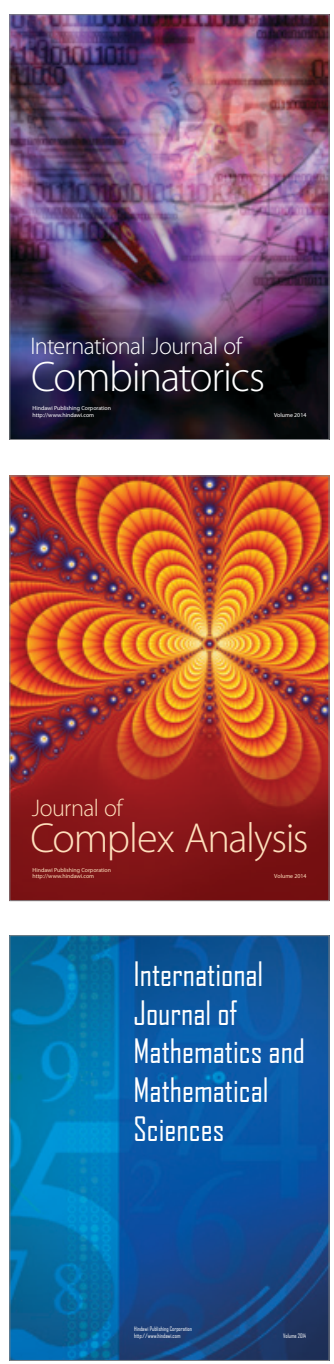
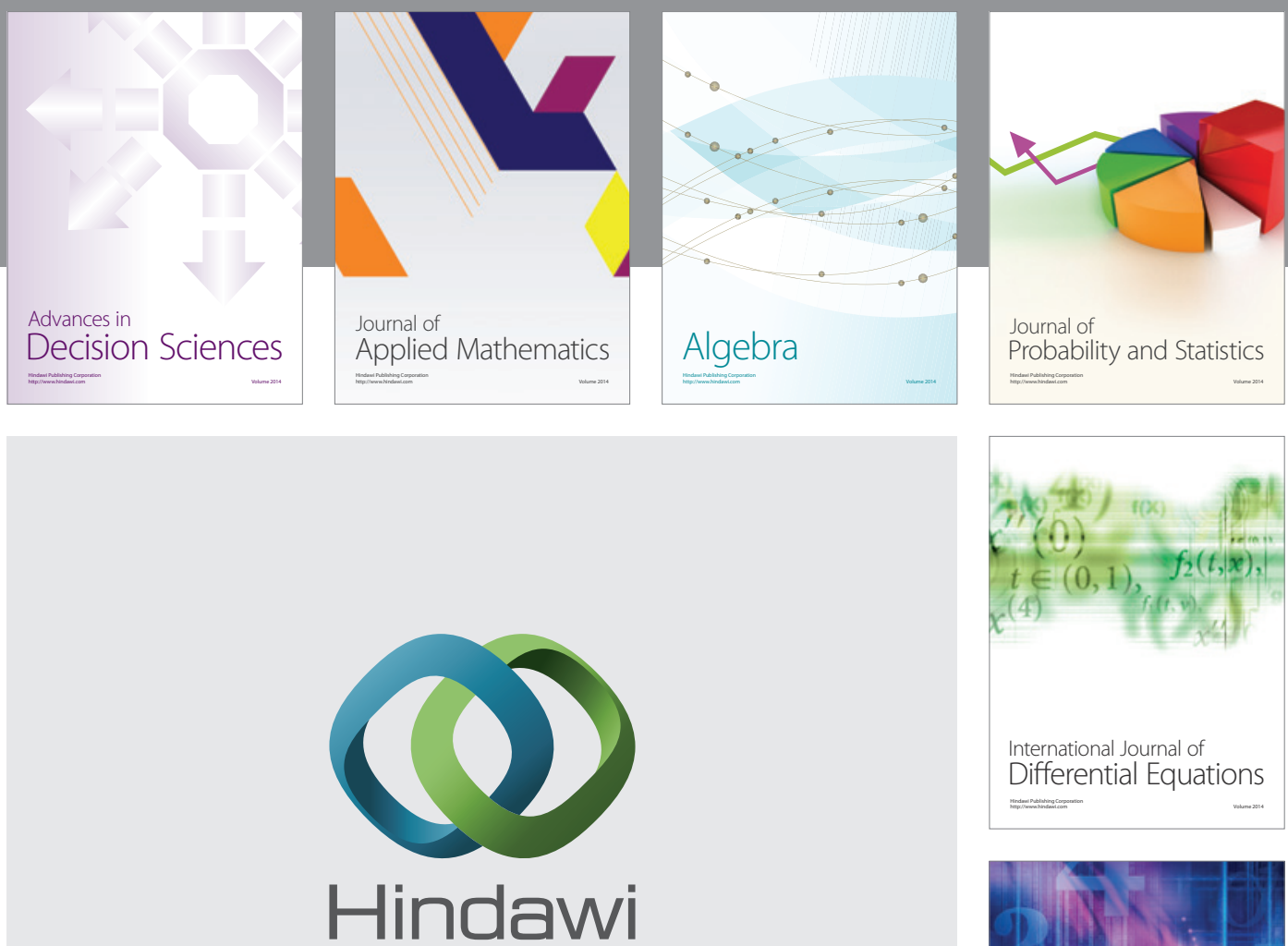

Submit your manuscripts at http://www.hindawi.com
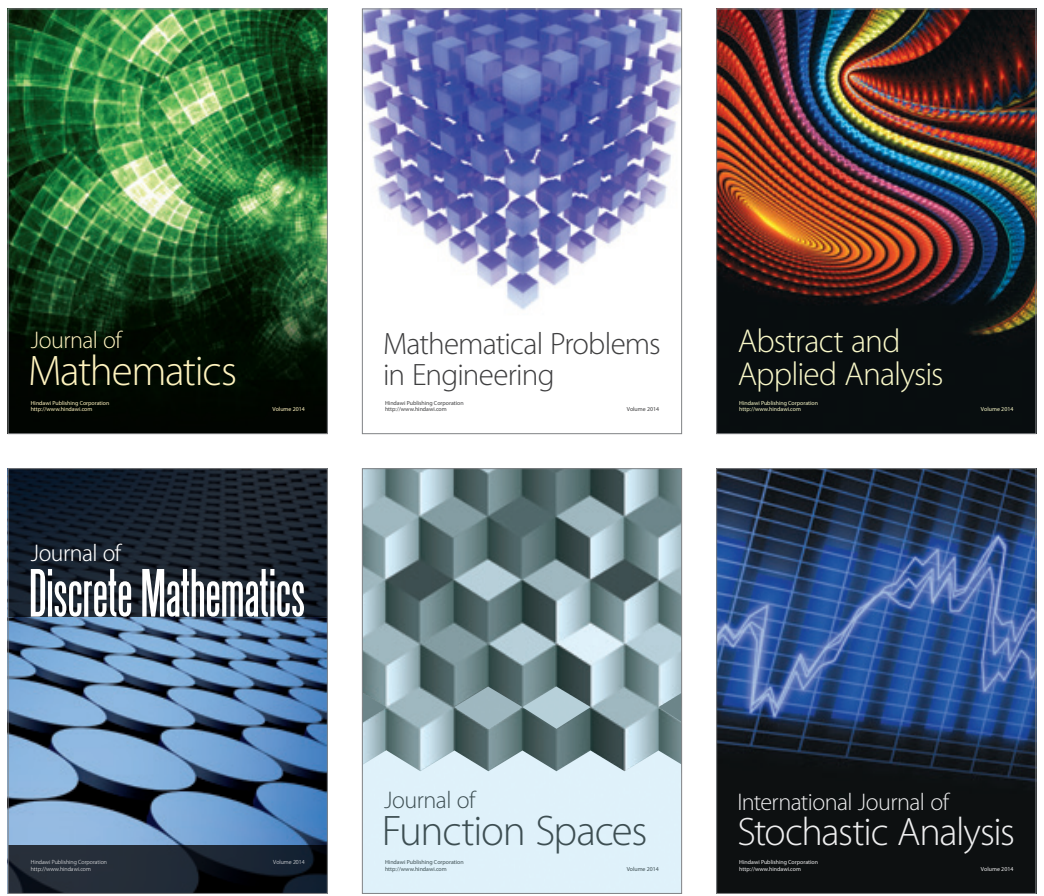

Journal of

Function Spaces

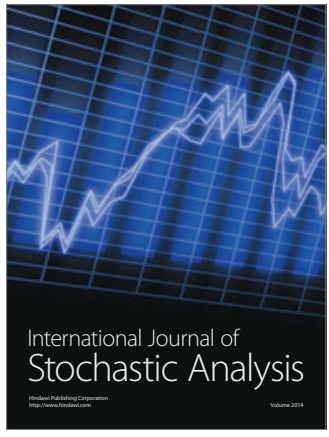

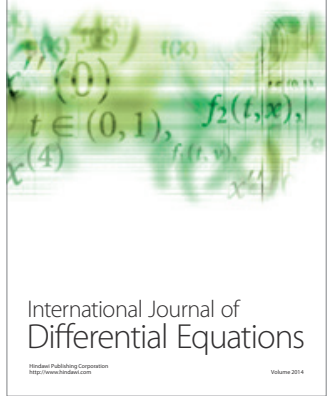
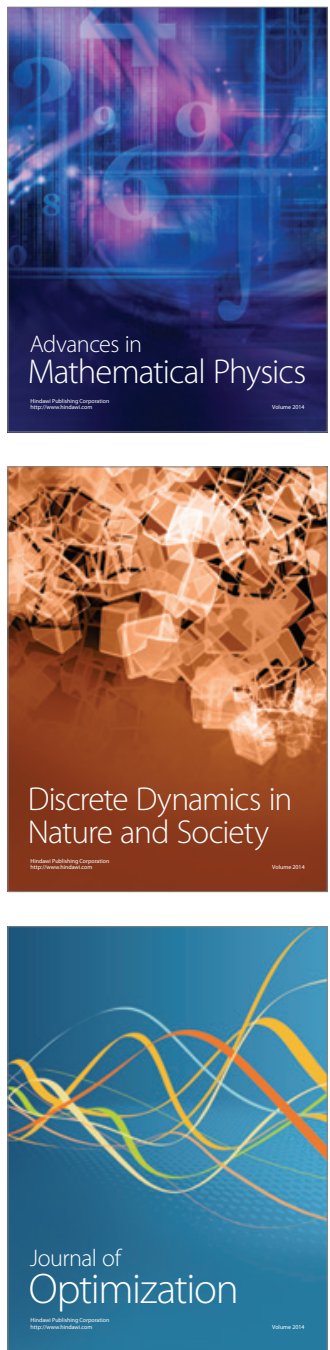